\title{
MLC1: A New Calcium-regulated Protein Conferring Calcium Dependence to Volume-regulated Anion Channels (VRAC) in Astrocytes.
}

\section{Maria Stefania Brignone}

Istituto Superiore di Sanità: Istituto Superiore Di Sanita

Angela Lanciotti

Istituto Superiore di Sanità: Istituto Superiore Di Sanita

Antonio Michelucci

Gabriele d'Annunzio University of Chieti and Pescara: Universita degli Studi Gabriele d'Annunzio Chieti

Pescara

\section{Cinzia Mallozzi}

Istituto Superiore di Sanità: Istituto Superiore Di Sanita

Serena Camerini

Istituto Superiore di Sanità: Istituto Superiore Di Sanita

\section{Luigi Catacuzzeno}

University of Perugia: Universita degli Studi di Perugia

\section{Luigi Sforna}

University of Perugia: Universita degli Studi di Perugia

\section{Martino Caramia}

University of Perugia: Universita degli Studi di Perugia

\section{Maria Cristina D'Adamo}

Free Mediterranean University: Universita LUM Jean Monnet

\section{Marina Ceccarini}

Istituto Superiore di Sanità: Istituto Superiore Di Sanita

\section{Paola Molinari}

Istituto Superiore di Sanità: Istituto Superiore Di Sanita

\section{Pompeo Macioce}

Istituto Superiore di Sanità: Istituto Superiore Di Sanita

\section{Gianfranco Macchia}

Istituto Superiore di Sanità: Istituto Superiore Di Sanita

\section{Tamara Corinna Petrucci}

Istituto Superiore di Sanità: Istituto Superiore Di Sanita

\section{Mauro Pessia}

United Arab Emirates University 


\section{Sergio Visentin}

Istituto Superiore di Sanità: Istituto Superiore Di Sanita

Elena Ambrosini ( $\square$ elena.ambrosini@iss.it)

Istituto Superiore di Sanità: Istituto Superiore Di Sanita https://orcid.org/0000-0002-4458-3442

\section{Research Article}

Keywords: Ca2+ release, ICl,swell, VRAC, CAMKII, CaM, leukodystrophy, rare diseases

Posted Date: January 3rd, 2022

DOI: https://doi.org/10.21203/rs.3.rs-1195518/v1

License: (c) (1) This work is licensed under a Creative Commons Attribution 4.0 International License.

Read Full License 
Title:

MLC1: a new calcium-regulated protein conferring calcium dependence to volume-regulated anion channels (VRAC) in astrocytes.

Brignone M.S. †, Lanciotti A.†, Michelucci A. †, Mallozzi C., Camerini S., Catacuzzeno L., Sforna L., Caramia M., D’Adamo M.C., Ceccarini M., Molinari P., Macioce P., Macchia G., Petrucci T.C., Pessia M., Visentin S. and Ambrosini E. *

- Brignone Maria Stefania, Istituto Superiore di Sanità, Department of Neuroscience, Viale Regina Elena 299, 00161, Rome, Italy. https://orcid.org/0000-0002-5174-9973

- Lanciotti Angela, Istituto Superiore di Sanità, Department of Neuroscience, Viale Regina Elena 299, 00161, Rome, Italy. https://orcid.org/0000-0003-1615-1770

- Michelucci Antonio, University G. d'Annunzio of Chieti, Department of Neuroscience, Imaging and Clinical Sciences, Via dei Vestini 31, Chieti, Italy; https://orcid.org/0000-00020720-3009.

- Mallozzi Cinzia, Istituto Superiore di Sanità, Department of Neuroscience, Viale Regina Elena 299, 00161, Rome, Italy. https://orcid.org/0000-0002-6126-9500

- Camerini Serena, Istituto Superiore di Sanità, Core Facilities (FAST), Viale Regina Elena 299, 00161, Rome, Italy. https://orcid.org/0000-0001-6131-4335

- Catacuzzeno Luigi, University of Perugia, Department of Chemistry, Biology and Biotechnology, Piazza Università 1, Perugia, Italy; https://orcid.org/0000-0002-4723-0650

- Sforna Luigi, University of Perugia, Department of Chemistry, Biology and Biotechnology, Piazza Università 1, Perugia, Italy; https://orcid.org/0000-0003-2145-3642

- Caramia Martino, University of Perugia, Department of Chemistry, Biology and Biotechnology, Piazza Università 1, Perugia, Italy; https://orcid.org/ 0000-0001-6939-216X

- D’Adamo Maria Cristina, LUM Giuseppe Degennaro University, Department of Medicine and Surgery, S.S. 100 Km. 18 - 70010, Casamassima, Bari, Italy. https://orcid.org/00000002-6758-6064

- Ceccarini Marina, Istituto Superiore di Sanità, National Centre for Rare Diseases, Viale Regina Elena 299, 00161, Rome, Italy. https://orcid.org/0000-0002-7021-4499

- Molinari Paola, Istituto Superiore di Sanità, National Centre for Drug Research and Evaluation (FARVA), Viale Regina Elena 299, 00161, Rome, Italy. https://orcid.org/0000-00028454-0121

- Macioce Pompeo, Istituto Superiore di Sanità, Department of Neuroscience, Viale Regina Elena 299, 00161, Rome, Italy. https://orcid.org/0000-0002-1829-9448

- Macchia Gianfranco, Istituto Superiore di Sanità, Core Facilities (FAST), Viale Regina Elena 299, 00161, Rome, Italy; https://orcid.org/0000-0001-6344-8724. 
- Petrucci Tamara Corinna, Istituto Superiore di Sanità, Department of Neuroscience, Viale Regina Elena 299, 00161, Rome, Italy. https://orcid.org/0000-0001-5529-541

- Pessia Mauro, College of Medicine and Health Sciences United Arab Emirates University, Al-Ain United Arab Emirates, Department of Physiology, Po Box 17666 Khalifa Bin Zayed Street, Tawam, United Arab Emirates. and Department of Physiology \& Biochemistry, Faculty of Medicine \& Surgery, UNIVERSITY OF MALTA, Msida, MSD2080, MALTA. https://orcid.org/0000-0002-2857-6795

- Visentin Sergio, Istituto Superiore di Sanità, National Center for Drug Research and Evaluation (FARVA), Viale Regina Elena 299, 00161, Rome, Italy. https://orcid.org/0000-00018510-6987

- Ambrosini Elena, Istituto Superiore di Sanità, Department of Neuroscience, Viale Regina Elena 299, 00161, Rome, Italy. https://orcid.org/0000-0002-4458-3442

*To whom correspondence should be addressed at Department of Cell Biology and Neuroscience, Istituto Superiore di Sanità, Viale Regina Elena 299, Rome 00161, Italy. Tel: +39 0649902037; Fax: +39 064957821; Email: elena.ambrosini@iss.i

† These authors equally contributed to this work

\section{Abstract}

MLC1 is a membrane protein highly expressed by brain perivascular astrocytes. Mutations in the MLC1 gene account for megalencephalic leukoencephalopathy with subcortical cysts (MLC), an incurable leukodystrophy characterized by macrocephaly, brain edema and cysts, myelin vacuolation and astrocyte swelling, causing cognitive and motor dysfunctions. It has been demonstrated that MLC1 mutations affect the swelling-activated $\mathrm{Cl}^{-}$currents $\left(\mathrm{I}_{\mathrm{Cl}, \text { swell }}\right)$ mediated by volume-regulated anion channel (VRAC) and the consequent regulatory volume decrease (RVD) and lead to abnormal activation of intracellular signaling pathways linked to inflammation/osmotic stress. Despite this knowledge, the MLC1 physiological role and MLC molecular pathogenesis are still elusive. Following the observations that $\mathrm{Ca}^{2+}$ regulates all the MLC1-modulated processes and that intracellular $\mathrm{Ca}^{2+}$ homeostasis is altered in MLC1-defective cells, we applied a multidisciplinary approach including biochemistry, molecular biology, video imaging, electrophysiology and proteomic techniques on cultured astrocytes to uncover new $\mathrm{Ca}^{2+}$-dependent signaling pathways controlling MLC1 function. Here, we revealed that MLC1 binds the $\mathrm{Ca}^{2+}$ effector proteins calmodulin (CaM) and $\mathrm{Ca}^{2+} / \mathrm{CaM}$-dependent protein kinase II (CaMKII) and, as result, changes its assembly, localization and functional properties in response to $\mathrm{Ca}^{2+}$ changes. Noteworthy, $\mathrm{CaM}$ binding to the $\mathrm{COOH}$ terminal promotes 
MLC1 trafficking to the plasma membrane, while CaMKII phosphorylation of the $\mathrm{NH}_{2}$-terminal potentiates MLC1 activation of $\mathrm{I}_{\mathrm{Cl} \text {,swell. }}$ Overall, these results revealed that MLC1 is a $\mathrm{Ca}^{2+}$-regulated protein linking VRAC function and, possibly, volume regulation to $\mathrm{Ca}^{2+}$ signaling in astrocytes. These findings open new avenues of investigations aimed at clarifying the abnormal molecular pathways underlying MLC and other diseases characterized by astrocyte swelling and brain edema.

Running title: MLC1 confers $\mathrm{Ca}^{2+}$ regulation to VRAC

Key words: $\mathrm{Ca}^{2+}$ release; Icl,swell; VRAC; CAMKII; CaM; leukodystrophy; rare diseases

\section{Author information}

+ Maria S. Brignone, Angela Lanciotti and Antonio Michelucci contributed equally and share first authorship.

\section{Contributions}

Study conception and design: M.S.B, A.L., A.M., C.M., S.C., L.C., L.S., M.C., M.C.D., M.C., P.M., P.M., G.M., M.P., S.V., E.A. Data curation: M.S.B, A.L., A.M., L.C., C.M. Acquisition of data: M.S.B., A.L. Investigation: M.S.B, A.L., A.M., C.M., S.C., L.S., M.C., M.C.D., M.C., P.M., P.M., G.M. Supervision: T.C.P., L.C., M.P., S.V, E.A. Writing-original draft: M.P., S.V. and E.A. Writing-review and editing: M.S.B., A.L., A.M., L.C., M.P., S.V. and E.A. All authors helped with critical reading of the manuscript and contributed to the ideas presented therein. All authors have read and approved the final version of the manuscript.

\section{Corresponding author}

Correspondence to Elena Ambrosini 


\section{Introduction}

MLC1 is a 377-amino acid membrane protein with eight predicted transmembrane domains and short cytoplasmic amino and carboxylic tails that shows very low similarity with some ion channels (reviewed in [1]). MLC1 is almost exclusively expressed in the brain where it localizes preferentially at astrocyte end-feet contacting blood vessels and meninges, and in the Bergmann glia of the cerebellum [2-4]. MLC1 proper function is still unknown, but genetic mutations affecting different regions of the MLC1 protein sequence are the main cause of the megalencephalic leukoencephalopathy with subcortical cysts disease (MLC). MLC is a rare congenital leukodystrophy where myelin degeneration, due to a primary astrocyte dysfunction, causes macrocephaly, ataxia, spasticity and progressive deterioration of motor and mental functions. MLC patients often suffer from epileptic seizures and their symptoms can worsen after minor head trauma or common infections $[1,5]$. Magnetic resonance imaging (MRI) showed diffuse white matter edema and the presence of subcortical cysts in MLC brain. The examination of some tissue biopsies revealed the existence of numerous vacuoles in the outer layers of the myelin sheaths and in astrocytes end-feet, along with some degrees of astrogliosis [5-8]. Mutations in the $M L C 1$ gene $[9,10]$ are responsible for the disease in $80 \%$ of patients, while in the others $20 \%$ mutations in the MLC1 chaperon protein GlialCAM have been found [11]. Several experimental evidences obtained using cellular and animal models of MLC showed that lack of functional MLC1 affects the activation of the VRAC-mediated chloride current $\left(I_{\mathrm{Cl}, \text { swell }}\right)$, an ubiquitous current activated by hypotonic stress which plays a fundamental role in cell volume regulation and water exchanges. These findings suggest that volume regulation and water flux defects may be the cause of the myelin degeneration characterizing MLC brain [12-17]. In addition, MLC1 was reported to downregulate specific intracellular signaling pathways (involving EGFR, ERK, PLC $\gamma$, NF-kB and STAT3 molecules) that are activated in astrocytes in response to inflammatory, oxidative and osmotic stress [18-20]. These latter observations lead to suppose that MLC1 mutations cause abnormally reactive, swollen astrocytes unable to rescue cellular and tissue homeostasis following brain insults. In line with this view, we reported MLC1 increase in perivascular astrocytes of brain tissue samples derived from patients affected by neurodegenerative and inflammatory diseases of the central nervous system (CNS), [20, 21]. Although all these results may explain some neuropathological deficits characterizing the MLC phenotype (brain edema, fluid cysts, aggravation of patient conditions after mild trauma or stress), MLC1 proper function and its role in cell volume 
regulation and $\mathrm{Cl}^{-}$current activation are still unknown. To shed light on MLC1 function here we explored the possibility that MLC1 activity is linked to intracellular $\mathrm{Ca}^{2+}$ signaling, since $\mathrm{Ca}^{2+}$ is an important regulator of $\mathrm{I}_{\mathrm{Cl}, \text { swell, }} \mathrm{RVD}$ and EGFR/ERK signaling pathways in glial cells [22, 26]. Moreover, our previous studies reported that MLC1 contributes to $\mathrm{Ca}^{2+}$ influx in astrocytes in response to osmotic stress, and, accordingly, defects in $\mathrm{Ca}^{2+}$ handling were observed in MLC pathological models $[18,27]$. Overall, these results suggest a reciprocal relationship between MLC1 and $\mathrm{Ca}^{2+}$ signaling in astrocytes that deserves further investigations. To this aim, we here integrated complementary experimental approaches encompassing biochemical, molecular biology, imaging, proteomic and electrophysiological techniques applied to astrocyte-based cellular models of MLC (human astrocytoma cells expressing MLC1 wild type or carrying pathological mutations) and primary mouse astrocytes. With these experiments, we revealed new $\mathrm{Ca}^{2+}$ dependent properties of the MLC1 protein that are of interest not only to clarify MLC pathogenesis but also to better understand the molecular mechanisms underlying other CNS disorders where astrocyte swelling and brain edema are observed. 
Materials and Methods

\section{Cell cultures and treatments}

Astrocyte-enriched cultures were generated from newborn CD1 Swiss mice and maintained in culture as previously described [28]. The U251 multiform glioblastoma (MG) cell line was kindly provided by Dr A. Calogero [29]. U251 cell lines expressing recombinant MLC1 wild type (WT) or mutated MLC1 (S280L), created as described in [30], and the newly generated cell lines expressing MLC1 T17A and T17D substitutions, obtained as described below, were grown in Dulbecco's modified Eagle's medium high glucose (DMEM, Euroclone, Ltd., UK), supplemented with 10\% FBS (Gibco BRL, Paisley, UK), 1\% penicillin/streptomycin (Euroclone, Ltd., UK) and $600 \mu \mathrm{g} / \mathrm{ml}$ of Geneticin G-418 (Sigma-Aldrich, Saint Louis, USA) for selection at $37^{\circ} \mathrm{C}$ in a $5 \% \mathrm{CO}_{2} / 95 \%$ air atmosphere. For treatments, cells were plated in serum-free (SF) medium and stimulated for 5 or 15 minutes ( $\mathrm{min}$ ) with different concentrations of ionomycin (Iono, 1 $\mu \mathrm{M}$, Sigma-Aldrich, Saint Louis, USA), thapsigargin (TG; 100 nM, Santa Cruz Biotechnology, Inc., Santa Cruz, California), adenosine triphosphate (ATP, $100 \mu \mathrm{M}$, Sigma-Aldrich, Saint Louis, USA) and Lanthanum chloride ( $\mathrm{LaCl}_{3}, 100 \mu \mathrm{M}$, Sigma-Aldrich, Saint Louis, USA). For hyposmotic stimulation, cells were treated for $30 \mathrm{~min}$ with isotonic solution $(140 \mathrm{mM}$ $\mathrm{NaCl}, 5 \mathrm{mM} \mathrm{KCl}, 2 \mathrm{mM} \mathrm{MgCl}$, 2 mM CaCl $2,20 \mathrm{mM}$ D-glucose, $5 \mathrm{mM} \mathrm{HEPES}$, pH 7.4) or with a hypotonic solution (in $\mathrm{Ca}^{2+}$-free conditions or with $2 \mathrm{mM} \mathrm{CaCl}_{2}$ ) prepared by adding $30 \%$ distilled water to the isotonic solution (hypo) [31, 32]. For high $\mathrm{K}^{+}$stimulation, cells were treated for $30 \mathrm{~min}$ with the same isotonic buffer in which $\mathrm{KCl}$ concentration was increased up to 60 $\mathrm{mM}$, as previously described $[21,33]$. To inhibit the interaction of $\mathrm{Ca}^{2+} / \mathrm{CaM}$ with protein targets, U251 MLC1-WT cells were pre-treated for 15 min with $1 \mu \mathrm{M}$ calmidazolium (Calbiochem, San Diego, CA) in isotonic solution, then co-stimulated for 15 min with $1 \mu \mathrm{M}$ calmidazolium in hypotonic solution.

Cycloheximide ( $\mathrm{CHX})$ treatment to assess MLC1 degradation kinetics, was carried out by stimulating cells with $\mathrm{CHX}(100 \mu \mathrm{g} / \mathrm{mL}$, Sigma-Aldrich, Darmstadt, Germany) for different time lengths $(1,3,4$ or 5 hours, h). After all stimulations, cells were washed in phosphate buffered saline (PBS), collected by scraping and centrifuged at $2700 \mathrm{~g}$ at $4^{\circ} \mathrm{C}$ for $10 \mathrm{~min}$. Cell pellets were solubilized and used for total protein extraction and western blot (WB) analysis, as described below. 
Generation of U251 cell lines expressing T17A or T17D substitution in MLC1 protein

Cell mutagenesis of the aminoacid (aa) Threonin (T) 17, recognized as the CaMKII phosphorylation site in the MLC1 sequence, into Alanine (A) and aspartic acid (D) (T17A and T17D, respectively) was obtained by using oligonucleotides containing the mutations required. To this aim the PQCXIN-MLC1-WT construct [30] was sequentially digested with Mfel (NEB, New England Biolabs Ltd., UK) and Notl (NEB, New England Biolabs Ltd., UK) and run on agarose gel electrophoresis. After restriction, the Mfel/Notl-pQCXIN-MLC1 sequence was eluted from the gel and purified with Gel Extraction Kit (Qiagen, Hilden, Germany). gBlocks ${ }^{\mathrm{TM}}$ Gene fragments (IDT, Integrated DNA Technologies, Inc.) containing T17A or T17D mutation were resuspended in water at a final concentration of $4 \mathrm{ng} / \mu \mathrm{l}$; each fragment (18 $\mathrm{ng}$ ) was then incubated for $1 \mathrm{~h}$ at $50^{\circ} \mathrm{C}$ with $100 \mathrm{ng}$ of the Mfel/Notl-digested pQCXIN-MLC1 in 1X Gibson Assembly ${ }^{\circledR}$ Master Mix (NEB, New England Biolabs Ltd., UK) in two separate $20 \mu$ reactions. $2.0 \mu$ l of each Gibson Assembly ${ }^{\circledast}$ reaction were used to transform DH5 $\alpha$ competent cells. After the cloning procedures, positive colonies were used to purify plasmidic DNA that was then subjected to sequencing analysis. Plasmids containing the desired mutation were used to generate stable U251 MG cell lines as previously described [30, 34].

Immunofluorescence (IF), fluorescence and confocal microscopy analysis U251 cells expressing MLC1 WT or carrying MLC1 mutations were grown on polylysine-coated coverslips and untreated or treated with different doses of Iono, TG, and ATP or with hyposmotic/high $\mathrm{K}^{+}$buffers for different time lengths (see above), and used for IF staining. After treatments, cells were fixed for 10 min with 4\% paraformaldehyde (PFA) and washed with PBS. After $1 \mathrm{~h}$ of incubation with blocking solution (5\% BSA in PBS), cells were incubated for 1 $h$ at room temperature (RT) with the following primary antibodies (Abs) diluted in phosphatebuffered saline (PBS) containing $0.025 \%$ Triton X-100: anti-MLC1 polyclonal Ab (pAb) (1:50, Atlas AB, AlbaNova University Center, Stockholm, Sweden), anti-Xpress monoclonal Ab (mAb) (1:50, ThermoFischer Scientific, Rockford, IL, USA, to detect the Xpress epitope present at the $\mathrm{NH}_{2}$ terminal of the recombinant MLC1), anti-EEA1 mAb (1:50, BD Transduction Laboratories, Lexington, KY), anti-CaM pAb (1:50, Santa Cruz Biotechnology, Inc., Santa Cruz, CA), antipCaMKII pAb (Santa Cruz Biotechnology, Inc., Santa Cruz, CA), anti-Calnexin mAb (1:70, BD Transduction Laboratories, Lexington, KY). As secondary Abs, a biotinilated goat anti-rabbit IgG H+L Ab (4.3 $\mathrm{mg} / \mathrm{ml}$; Jackson Immunoresearch Laboratories, West Grove, PA) followed by 
streptavidin-TRITC ( $2 \mu \mathrm{g} / \mathrm{ml}$; Jackson), and Alexa Fluor 488 goat anti-mouse IgG Ab (1:300, Invitrogen, Milan, Italy) were used. To stain actin filaments, a fluorescein (FITC)-conjugated phallacidin high-affinity F-actin probe (1:30, Invitrogen) was used. Coverslips were washed, sealed in Fluoroshield with 40,6-diamidino-2-phenylindole (DAPI), (F6057, Sigma-Aldrich, Saint Louis, USA), and analyzed with a fluorescence microscope (Carl Zeiss, Jena, Germany), equipped with a digital camera (ZEISS Axiocam 512); images were acquired by using ZEN 3.1 blu edition software.

\section{Protein extract preparation and western blotting (WB)}

Total protein extracts from astrocytoma cell lines and mouse astrocytes were obtained as previously described [Lanciotti et al., 2010; 2012]. Equal amounts of proteins (30 or $40 \mu \mathrm{g}$ ) were resolved on SDS-PAGE using gradient (4-12\%) pre-casted gels (Thermo Fisher Scientific, CA), and transferred onto a nitrocellulose membrane. Nitrocellulose membranes were blotted overnight (ON) at $4^{\circ} \mathrm{C}$ using anti-MLC1 pAb (1:1500, in-house generated; Ambrosini et al., 2008), anti-Actin mAb (1:2000, Santa Cruz Biotechnology, Santa Cruz, CA, USA), antiGST mAb (1:1000, Santa Cruz Biotechnology, Inc., Santa Cruz, CA), anti-pCaMKII pAb (1:200, Santa Cruz Biotechnology, Inc., Santa Cruz, CA), anti-PP1 pAb (1:1000, Santa Cruz Biotechnology, Inc., Santa Cruz, CA), anti-PP2A pAb (1:1000, Santa Cruz Biotechnology, Inc., Santa Cruz, CA) in PBS $+3 \%$ BSA. After washings in tris buffered saline (TBS), membranes were incubated with horseradish peroxidase-conjugated anti-mouse or anti-rabbit Abs (1:5000; Biorad Laboratories, Hercules, CA, USA) for $1 \mathrm{~h}$ at RT. Immunoreactive bands were visualized using an enhanced chemiluminescence reagent (Pierce, ThermoFisher Scientific, Rockford, IL, USA), according to the manufacturer's instructions, and exposed ON a Bio-Rad ChemiDoc XRS system. Densitometric analyses of WB experiments were performed using NIH ImageJ software (National Institutes of Health, Bethesda, MD, USA) or Bio-Rad ChemiDoc XRS system. Quantification of protein loading content was carried out using a bicinchonic acid assay (BCA kit; Thermo Scientific, Waltham, MA, USA).

\section{Fura-2-based $\mathrm{Ca}^{2+}$ imaging}

Cytoplasmic $\mathrm{Ca}^{2+}$ was measured by the fluorescence video-imaging technique with the $\mathrm{Ca}^{2+}$ indicator Fura-2-AM (Invitrogen, Thermo Fisher Scientific, USA). U251 cells seeded on poly-lysine-coated glass coverslips, were kept in the dark (50 min) with $2 \mu \mathrm{M}$ Fura- 
2-AM dissolved in recording buffer (see below) at RT. Loading and recording buffer had the following composition (mM): $140 \mathrm{NaCl}, 5 \mathrm{KCl}, 1 \mathrm{MgCl}_{2}, 2.5 \mathrm{CaCl}_{2}, 5.5$ D-glucose, 10 $\mathrm{HEPES} / \mathrm{NaOH}$, at RT, pH7.4). In $\mathrm{Ca}^{2+}$-free solutions, $\mathrm{Ca}^{2+}$ was replaced by $\mathrm{MgCl}_{2}$ and $0.5 \mathrm{mM}$ EGTA was added (0-Ca ${ }^{2+}$ solution). Coverslips were placed in the perfusion chamber on the stage of an inverted microscope (Axiovert 35, Zeiss, Germany) and perfused with buffer solution. In order to avoid the contamination of even the least amount of $\mathrm{Ca}^{2+}$, for $\mathrm{Ca}^{2+-}$ free experiments also the perfusion chamber was filled with $0-\mathrm{Ca}^{2+}$ solution. A custom-made local solution exchange system allowed the solution bathing the cells to be rapidly switched between control and test solutions. Excitation wavelengths at 340 and $380 \mathrm{~nm}$ were applied every 2 seconds (sec) by a monochromator (Polychrome II, Photonics, Germany) and the emitted light $(510 \mathrm{~nm})$ was recorded by a CCD digital camera (PCO, Sensicam, Germany) connected to a computer. The Imaging Workbench software (INDEC Systems, CA, USA) was used for recording and initial data analysis. Origin 7.5 software (Microcal Software, USA) was used for further analysis and graphical presentation. $\mathrm{Ca}^{2+}$ concentrations were expressed as the ratio of emissions at $340 \mathrm{~nm}$ to $380 \mathrm{~nm}$.

\section{Recombinant protein preparation and calmodulin (CaM) binding assay}

The N-terminal and C-terminal cytoplasmic regions of human MLC1 (aa 1-56 and aa 320-377) fused with GST were obtained in BL21 E.coli and purified by affinity chromatography as previously described [35]. GST and GST fusion protein were used in in vitro protein binding and in in vitro phosphorylation assays [35]. Agarose-bound CaM (Sigma-Aldrich, Saint Louis, USA) (100 $\mu$ l of $50 \%$ suspension) equilibrated in $150 \mathrm{mM} \mathrm{NaCl}, 20 \mathrm{mM}$ Tris-HCL pH 7.4 and $2 \mathrm{mM}$ $\mathrm{CaCl}_{2}$ was incubated with $200 \mu \mathrm{g}$ GST-MLC1 N-terminal (GST-MLC1-N-t) or C-terminal (GSTMLC1-C-t) region ON at $4^{\circ} \mathrm{C}$. After extensive washes with equilibration buffer without $\mathrm{CaCl}_{2}$, bound proteins were eluted with equilibration buffer containing $10 \mathrm{mM}$ EDTA. Eluted proteins were then analyzed by WB.

\section{In vitro kinase assay for CaMKII}

The phosphorylated active enzyme CaMKII was immunoprecipitated from U251 cells by the use of a specific anti-pCaMKII Ab. To this aim, U251 cells were solubilized at $0^{\circ} \mathrm{C}$ with RIPA buffer (25 mM Tris-HCl, pH 7.5, $0.15 \mathrm{M} \mathrm{NaCl}$, 1\% (w/v) Triton X-100, 1\% (v/v) Na-deoxycholate, $0.1 \%(\mathrm{v} / \mathrm{v}) \mathrm{SDS}, 0.1 \mathrm{mM} \mathrm{Na}_{3} \mathrm{VO}_{4}, 1 \mathrm{mM}$ PMSF, phosphatase and protease inhibitor cocktails) 
for $30 \mathrm{~min}$. After centrifugation at $12000 \mathrm{~g}$ for $10 \mathrm{~min}$ at $4^{\circ} \mathrm{C}$, the supernatants were precleared with $20 \mu$ of Protein A/G Plus beads prepared as a $50 \%(v / v)$ suspension for $2 \mathrm{~h}$ at $4^{\circ} \mathrm{C}$. The supernatants $(1 \mathrm{mg} / \mathrm{ml})$ were then incubated $\mathrm{ON}$ at $4^{\circ} \mathrm{C}$ in a rotating wheel with anti-

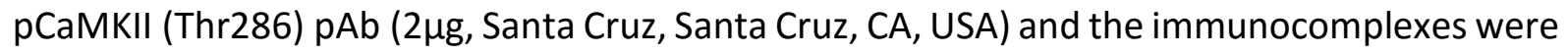
precipitated by addition of Protein A/G Plus bead suspensions ( $50 \% \mathrm{v} / \mathrm{v})$. The immunoprecipitates were collected by centrifugation and washed twice with RIPA buffer and twice with TBS. Bound protein was used to phosphorylate in vitro the agarose-bound-GST, GST N-terminal and GST C-terminal regions of MLC1. The in vitro kinase assay was performed by incubating the immunoprecipitated pCaMKII or commercial recombinant purified pCaMKII $(0.5 \mu \mathrm{g}$, Invitrogen, Thermo Fisher Scientific, USA) with recombinant proteins in kinase buffer (25 $\mathrm{mM}$ Hepes, pH 7.4, $50 \mathrm{mM} \mathrm{KCl}, 10 \mathrm{mM} \mathrm{MgCl}$, 1 mM DTT, 2 mM CaCl $2,0.1$ mM PMSF, phosphatase inhibitor cocktail) containing $2 \mu \mathrm{M} \mathrm{CaM}$ and $1-2 \mu \mathrm{Ci}\left[\gamma^{32} \mathrm{P}\right]$ ATP (>3000 Ci/mmol) for $10 \mathrm{~min}$ at $30^{\circ} \mathrm{C}$ under gentle stirring. When indicated, KN93, a cell permeable inhibitor of CaM kinase II, (10 $\mu \mathrm{M}$, Sigma-Aldrich, Saint Louis, USA) was used in the reaction mixture. The kinase reaction was stopped by adding 4 X SDS loading buffer and the samples were resolved on $12 \%$ SDS-PAGE. The dried gels were exposed to X-ray film for autoradiography. When indicated, an exogenous substrate, such as Myelin basic protein (MBP), was added to the reaction mixture.

\section{Mass spectrometry analysis}

For mass spectrometry analysis, the phosphorylation reaction was carried out in the kinase buffer (see above) containing $2 \mu \mathrm{M} \mathrm{CaM}$ and $0.3 \mathrm{mM}$ ATP using the commercial recombinant purified pCaMKII. After incubation, the beads were washed in $50 \mathrm{mM}$ ammonium bicarbonate. Proteins eluted from the beads were separated on a 1D-gel NuPAGE 4-12\% (Novex, Invitrogen, Carlsbad, CA, USA) and stained with Coomassie blue (Colloidal Blue Staining kit, Invitrogen). Colored bands were cut, reduced with DTT, alkylated with iodoacetamide, and finally digested with trypsin (Promega, Madison, WI, USA), , Asp (Promega, Madison, WI, USA) or GluC (Sigma-Aldrich, Saint Louis, USA) as described in [36]. To identify phosphorylated sites, peptide mixture was analyzed by nanoflow-reversed-phase liquid chromatography tandem mass spectrometry (RP-LC-MS/MS) using an HPLC Ultimate 3000 (DIONEX, Sunnyvale, CA U.S.A) connected on line with a linear Ion Trap (LTQ, ThermoElectron, San Jose, CA). Peptides 
were desalted in a trap-column (AcclaimPepMap100 C18, LC Packings, DIONEX) and then separated in a reverse phase column, a $10 \mathrm{~cm}$ long fused silica capillary (SilicaTipsFS 360-75-8, New Objective, Woburn, MA, USA), slurry-packed in-house with $5 \mu \mathrm{m}, 200 \AA$ pore size C18 resin (Michrom BioResources, CA). Peptides were eluted using a linear gradient from 96\% aqueous phase ( $5 \% \mathrm{ACN}$ and $0.1 \%$ formic acid) to $60 \%$ organic buffer ( $95 \% \mathrm{ACN}$ and $0.1 \%$ formic acid) in $30 \mathrm{~min}$, at $300 \mathrm{nl} / \mathrm{min}$ flow rate. Analyses were performed in positive ion mode and the HV Potential was set up around 1.5-1.8kV. A data-dependent strategy was used to fragment the five more intense ions present in each full MS scan by collision-induced dissociation by CID with 35\% collision energy. Tandem mass spectra were interpreted through the SEQUEST algorithm [37] taking into account the potential for phosphorylation on Ser, Thr, or Tyr residues and also manually reviewed. A MS/MS was considered legitimately matched with cross-correlation scores of $1.8,2.5$, and 3 respectively for one, two, and three charged peptides and a probability cut-off for randomized identification of 0.001. Data are available via ProteomeXchange with identifier PXD030549.

\section{Electrophysiology}

The whole cell dialyzed configuration was used for electrophysiological recordings from U251 cells. Currents and voltages were amplified with a HEKA EPC-10 amplifier (List Medi-cal, Darmstadt, Germany), digitized with a 12 bit A/D converter (TL-1, DMA interface; Axon Instruments, Foster City, CA), and analyzed with the software Patch-Master package (version 2_60, ELEKTRONIK) and Microcal Origin 8.0. For on-line data collection, macroscopic currents were filtered at $3 \mathrm{kHz}$ and sampled at $200 \mu \mathrm{s} /$ point. The external standard solution contained: $\mathrm{NaCl}$ $140 \mathrm{mM}, \mathrm{KCl} 5 \mathrm{mM}, \mathrm{CaCl}_{2} 2 \mathrm{mM}, \mathrm{MgCl}_{2} 2 \mathrm{mM}$, MOPS $5 \mathrm{mM}$, glucose $10 \mathrm{mM}$, (pH 7.40). The external $\mathrm{Ca}^{2+}$-free solution contained: $\mathrm{NaCl} 140 \mathrm{mM}, \mathrm{KCl} 5 \mathrm{mM}, \mathrm{MgCl}_{2} 4 \mathrm{mM}, \mathrm{MOPS} 5 \mathrm{mM}$, glucose $10 \mathrm{mM}$, (pH 7.40). The internal solution contained: $\mathrm{KCl} 155 \mathrm{mM}$, EGTA-K $1 \mathrm{mM}$, MOPS $5 \mathrm{mM}, \mathrm{MgCl}_{2} 1 \mathrm{mM}$ (pH 7.20). Access resistances ranged between 8 and $15 \mathrm{M} \Omega$ and were actively compensated to 50\%. 4-[(2-Butyl-6,7-dichloro-2-cyclopentyl-2,3-dihydro-1-oxo-1Hinden-5-yl)oxy] butanoic acid (DCPIB)(Tocris Bioscience), a potent inhibitor of $\mathrm{I}_{\mathrm{Cl}, \text { swell }}$ mediated by VRAC, was dissolved in dimethyl sulfoxide (DMSO, Sigma-Aldrich) at the stock concentration of $10 \mathrm{mM}$ and used at the final concentration of $10 \mu \mathrm{M}$ in the recording solution. This concentration completely blocks the $\mathrm{I}_{\mathrm{Cl} \text {,swell }}$ mediated by VRAC as previously reported (Sforna 
et al., 2017). N-[2-[[[3-(4-Chlorophenyl)-2-propenyl]methylamino]methyl]phenyl]-N-(2-hydroxyethyl)-4 methoxybenzenesulphonamide (KN-93,Tocris Bioscience), the specific inhibitor of CaMKII, was DMSO at the stock concentration of $10 \mathrm{mM}$ and used at the final concentration of $10 \mu \mathrm{M}$ in the recording solution. The highest DMSO concentration in the recording solutions was $0.1 \%$. To activate the $\mathrm{I}_{\mathrm{Cl}, \text { swell }}$ through hypotonicity, we used the $30 \%$ hypotonic solution prepared as described above. To eliminate the contribution of both voltage-and $\mathrm{Ca}^{2+}$-activated $\mathrm{K}^{+}$currents, estimates of $\mathrm{I}_{\mathrm{Cl}, \text { swell }}$ were taken at $-80 \mathrm{mV}$, the equilibrium potential for $\mathrm{K}^{+}$, in the presence of $3 \mathrm{mM}$ extracellular TEA, a blocker of large-conductance $\mathrm{Ca}^{2+}$-activated $\mathrm{K}^{+}$channels (BK). All reagents were fresh daily solubilized at the concentrations stated, and bath applied with a gravity perfusion system. Experiments were carried out at RT $\left(18-22^{\circ} \mathrm{C}\right)$.

\section{Expression of MLC1 protein in Xenopus oocytes}

The human MLC1 CDNA, obtained as described in [4], was introduced into the pBF oocyte expression vector using the following sense and antisense primers: $5^{\prime}$-CCG AAT TCG GAT GAC CCA GGA GCC A-3' (sense) and 5'-GAA GAT CTT CTC ACT GGG CCA TTT G -3' (antisense). Capped mRNAs were synthesized in vitro, as previously described [38].To assess by WB the expression of MLC1 constructs injected in oocytes, 10 injected oocytes were suspended in $1 \mathrm{ml}$ of $5 \mathrm{mM}$ Tris $\mathrm{pH} 8.0$ containing $1 \mathrm{mM}$ EDTA, $1 \mathrm{mM}$ EGTA, 2 mM PMSF and a cocktail of protease inhibitors (Sigma Chemicals, St. Louis. MO) and lysed using a sequence of mechanical passages through 20 and 27 gauge needles. The homogenates were centrifuged at $700 \mathrm{~g}$ for $5 \mathrm{~min}$, and the obtained supernatants then centrifuged at $100000 \mathrm{~g}$ for $1 \mathrm{~h}$. Equal volumes of cleared homogenates were resolved on SDS-PAGE as described above. In vitro transcribed mRNA encoding the MLC1 WT protein was microinjected into oocytes and WB analysis was performed to assess proper expression of the protein. This analysis showed that maximal MLC1 expression occurred in oocytes $48 \mathrm{~h}$ after mRNA injection. Therefore, oocytes were collected at this time point and used to perform two-electrode voltage-clamp recordings in control condition and during the application of the hyposmotic solution to induce the endogenously expressed $I_{\text {Clswell. }}$

\section{Statistical Analysis}

All the statistical analyses were performed using GraphPad prism software (USA). Results were expressed as mean \pm standard error of mean (SEM). Data were first subjected to normality 
test (D’Agostino and Pearson Omnibus Normality test); when data followed a normal distribution, a Student-t test was applied; otherwise, non-parametric tests, such as Wilcoxon test or Kruskal-Wallis test, followed by Dunn's Multiple Comparison post hoc test when necessary were performed. Statistically significant $p$ values are $* p<0.05, * * p<0.01$ and $* * * p<$ 0.001 , while not significant data are indicated with the "ns" abbreviation. 
Results

$\mathrm{Ca}^{2+}$ influx and $\mathrm{Ca}^{2+}$ release differently affect MLC1 protein assembly and trafficking to the plasma membrane

To study the possible relationships between MLC1 protein and intracellular $\mathrm{Ca}^{2+}$ signaling in astrocytes, we first analyzed whether MLC1 dimer formation and trafficking toward the plasma membrane (PM), two protein features indicative of $\operatorname{MLC1}$ functional activation [4, 39, 40], were influenced by variations of cytosolic $\mathrm{Ca}^{2+}$ levels. To this aim, we used the already characterized U251 human astrocytoma cells stably overexpressing the human recombinant MLC1 wild-type (MLC1WT), [Lanciotti et al., 2012; Brignone et al., 2014], along with U251 cells expressing the S280L (MLC1S280L) MLC1 pathological mutant and primary mouse astrocytes encoding the endogenous MLC1 protein as controls of the appropriateness of the astrocytoma-based model to study the physiological function of MLC1.

Cytoplasmic $\mathrm{Ca}^{2+}$ raise is the result of a combination of $\mathrm{Ca}^{2+}$ entrance from extracellular milieu and $\mathrm{Ca}^{2+}$ release from internal stores, mainly the endoplasmic reticulum (ER). We firstly thought to modulate intracellular $\mathrm{Ca}^{2+}$ levels by stimulating cells with lono, a $\mathrm{Ca}^{2+}$ ionophore capable of causing cytoplasmic $\mathrm{Ca}^{2+}$ raise mainly by favoring extracellular $\mathrm{Ca}^{2+}$ influx [41].By performing Western blot (WB) experiments, we observed that $\mathrm{U} 251$ cell treatment with $1 \mu \mathrm{M}$ of lono for 15 min caused a decrease of the dimeric/PM associated form of MLC1 (Fig. 1A, arrow). Accordingly, IF images of lono-treated cells showed lower levels of MLC1 at PM when compared to untreated U251 cells, indicating that in these cells MLC1 protein internalization/endocytosis is favored in response to cytoplasmic $\mathrm{Ca}^{2+}$ raise due to $\mathrm{Ca}^{2+}$ influx (Fig. 1B). Then, we monitored MLC1 dimerization and trafficking in response to $\mathrm{Ca}^{2+}$ release from intracellular stores by treating cells with: i) TG, a non-competitive inhibitor of the ER Ca ${ }^{2+}$ ATPase (SERCA) that causes a massive $\mathrm{Ca}^{2+}$ release from the ER followed by capacitive $\mathrm{Ca}^{2+}$ entry (CCE) of external $\mathrm{Ca}^{2}$ needed for ER refilling and ii) ATP, which, by binding the ionotropic P2 receptors, triggers the production of inositol 1,4,5-trisphosphate (InsP3) and the subsequent InsP3-mediated $\mathrm{Ca}^{2+}$ release from the ER, followed by CCE [42].

Moreover, to assess if also CCE has a role on MLC1 stimulation, the above treatments were performed in absence or presence of lanthanum chloride $\left(\mathrm{LaCl}_{3}\right)$, inhibits CCE by acting on PM Ca${ }^{2+}$ permeant channels [43]. WB of protein extracted from U251 cells after a 5 min stimulation with 100 nM of TG (experimental conditions causing a rapid and sustained $\mathrm{Ca}^{2+}$ release in glioma cells) [44], 
showed an increase of the MLC1 dimeric, membrane associated form when compared to unstimulated cells (Fig. 1C, arrow). Consistent with these observations, an increase of the MLC1 dimer formation was observed in cells treated 5 min with 100 mM ATP (Fig. 1E, arrow) . Noteworthy, in both $\mathrm{Ca}^{2+}$ release-stimulating conditions, MLC1 activation was not affected by the co-treatment with $\mathrm{LaCl}_{3}$ (Fig. 1C,E), revealing that CCE activated after ER Ca ${ }^{2+}$ release did not participate to MLC1 activation. According to WB results, IF experiments confirmed that MLC1 was more localized at PM in response to TG or ATP treatment (Fig. 1 D,F).

As observed in astrocytoma cells, also the endogenous MLC1 protein expressed in primary mouse astrocytes differently responded to Iono, TG and ATP, with MLC1 dimeric form being decreased after lono treatment and increased in response to $\mathrm{ER} \mathrm{Ca}^{2+}$ release due to TG and ATP stimulation (Fig. SD1, A-C, arrows). In these cells TG and ATP also increased the MLC1 protein monomers (Fig. SD1, B-C, asterisks), suggesting a possible effect of these treatments on MLC1 monomer stability or on MLC1 transcriptional activation. Both mechanisms will be further investigated.

To exclude that the $\mathrm{Ca}^{2+}$ responsiveness of the MLC1 protein was due to unspecific protein release from ER induced by TG/ATP treatment, we also analyzed U251 cells stably expressing the recombinant MLC1-S280L pathological mutant $[30,45]$. These experiments showed no changes in MLC1 mutant protein dimerization in response to the above treatments (Fig. SD2), confirming that only the functional active WT protein is sensitive to intracellular $\mathrm{Ca}^{2+}$ changes. Overall, these findings demonstrate that $\mathrm{MLC} 1$ is a $\mathrm{Ca}^{2+}$ sensitive protein whose assembly and trafficking are favored by $\mathrm{Ca}^{2+}$ release from intracellular stores and inhibited by external $\mathrm{Ca}^{2+}$ influx.

To confirm the intracellular $\mathrm{Ca}^{2+}$ sources stimulating MLC1 activation in U251 cells, we analyzed the $\mathrm{Ca}^{2+}$ transients induced by the application of the same concentrations of the above mentioned agents using Fura-2-based fluorescence video-imaging. TG and ATP fast and long lasting (15 min) application to $\mathrm{U} 251$ cells induced a fast raising $\mathrm{Ca}^{2+}$ transient followed by a slow plateau phase, which was absent when recording in the presence of $\mathrm{LaCl}_{3}(100 \mu \mathrm{M}, 15 \mathrm{~min})$. Such time-course was compatible with a fast release of $\mathrm{Ca}^{2+}$ from the internal stores followed by CCE, which was abrogated by the trivalent cation $\mathrm{La}^{3+}$. $\mathrm{Ca}^{2+}$ transient induced by lono was mainly due to CCE-independent $\mathrm{Ca}^{2+}$ entry, and only slightly from $\mathrm{Ca}^{2+}$ release, as depicted from the transients recorded in $0-\mathrm{Ca}^{2+}$ or $\mathrm{La}^{3+}$ (Fig. SD3, A-C).

\section{Calmodulin binds MLC1 at the C-terminal end and confers $\mathrm{Ca}^{2+}$ dependence to MLC1 trafficking}


The above results highlight the notion that MLC1 WT localization and (potentially) functional properties are affected by $\mathrm{Ca}^{2+}$ changes, although they do not unequivocally support the fact that these effects are due to an intrinsic MLC1 feature rather than depending on other unidentified factors. To answer this question, we investigated the structural features that confer $\mathrm{Ca}^{2+}$ sensitivity to MLC1. We first analyzed MLC1 primary sequence using different protein databases finding that MLC1 is not included within the list of the known proteins containing the signature and profile of the EFhand $\mathrm{Ca}^{2+}$-binding domain (Expasy, Prosite data base, PDOC00018 documentation), characterizing $\mathrm{Ca}^{2+}$-binding proteins [46]. However, a putative calmodulin (CaM) binding consensus motif was identified at the $\mathrm{COOH}$ terminal domain of the MLC1 amino acid (aa) sequence (aa 323-339; http://calcium.uhnres.utoronto.ca/ctdb/ctdb/sequence.html) (Fig. 2A,B). CaM is a Ca ${ }^{2+}-$ binding protein ubiquitously expressed in eukaryotes able to regulate in a $\mathrm{Ca}^{2+}$-dependent manner biological activities of many cellular proteins, including ion channels and transporters [47]. At the $\mathrm{Ca}^{2+}$ concentrations of a quiescent cells $\left(10^{-7}-10^{-8} \mathrm{~mol} \mathrm{I}^{-1}\right), \mathrm{CaM}$ is inactive, but it undergoes rapid and activating conformational changes as $\left[\mathrm{Ca}^{2+}\right]$ i rises upon $\mathrm{Ca}^{2+}$-elevating stimuli. When the cytoplasmic $\mathrm{Ca}^{2+}$ level increases, four $\mathrm{Ca}^{2+}$ ions bind to $\mathrm{CaM}$, and the $\mathrm{Ca}^{2+}-\mathrm{CaM}$ complex interacts with the target proteins [48, and references therein]. CaM target proteins are generally unable to bind $\mathrm{Ca}^{2+}$ per se and use CaM as a $\mathrm{Ca}^{2+}$ sensor and signal transducer [48]. To verify whether MLC1 $\mathrm{Ca}^{2+}$ sensitivity was due to its interaction with CaM, we performed a pull-down assay using CaM-agarose resin and recombinant MLC1- $\mathrm{NH}_{2}$ or $\mathrm{MLC1}-\mathrm{COOH}$ terminal domains fused to glutation-S-transferase: GSTMLC1-NH 2 (N-terminal aa 1-56, N-t) and GST-MLC1-COOH (C-terminal aa 320-377, C-t). The binding to CaM-agarose was carried out in presence of $\mathrm{Ca}^{2+}$ and the bound proteins were eluted with EDTA. These experiments revealed that CaM/MLC1 binding occurs only when the MLC1-C-t, and not the MLC1-N-t peptide was used (Fig. 2C), in agreement with the identification of the putative CaM consensus sequence in this domain. IF stainings to analyze CaM/MLC1 co-localization in intact cells were performed using anti-MLC1 pAb in combination with anti-CaM mAb. These experiments showed a very low expression of CaM in U251 cells in not-stimulated conditions. Increased CaM expression and co-localization with MLC1 in the perinuclear areas and ER compartment were observed after cell treatment with hypotonic and high $\mathrm{K}^{+}$solutions (Fig. SD4A-C), both conditions inducing $\mathrm{Ca}^{2+}$ release/CaM activation in astrocytes $[49,50]$ and also stimulating MLC1 trafficking [35, 51]. Since direct interaction with CaM is critical for the correct activity of several PM proteins as it controls protein assembly and trafficking $[52,53]$, we used calmidazolium, a recognized CaM antagonist [54] to monitor the effect of CaM inhibition on MLC1 dimerization, trafficking and PM translocation. WB 
and IF analyses of U251 cells in control conditions and after hyposmotic stimulation that induces MLC1 dimerization and translocation to PM $[30,51]$ were performed in presence or absence of 1 $\mu \mathrm{M}$ of calmidazolium. Panels D and E-G of Fig. 2 show that 15 min of hyposmotic stimulation favored MLC1 dimer formation and trafficking to the PM and that both processes were strongly inhibited by a 15 min pre-treatment with calmidazolium. These data are consistent with the notion that the $\mathrm{Ca}^{2+}$ sensor CaM binds to the $\mathrm{C}$ terminus of MLC1 protein, conferring $\mathrm{Ca}^{2+}$ dependence to its assembly and trafficking to the PM.

\section{CaM-kinase II and protein phosphatases PP1A and PP2A bind the C-terminus of MLC1}

To go further in the identification of the repertoire of MLC1 $\mathrm{Ca}^{2+}$-dependent mechanisms, we also investigated the possible involvement of the CaMKII in the regulation of MLC1 functions in response of cytosolic $\mathrm{Ca}^{2+}$ changes. CaMKII is a serine/threonine protein kinase regulated by the $\mathrm{Ca}^{2+} / \mathrm{CaM}$ complex and recognized as a crucial mediator of many physiological effects caused by elevations of intracellular $\mathrm{Ca}^{2+}[48]$. To verify the possible binding of MLC1 to CaMKII, we performed a pull-down assay of rat brain protein extracts using recombinant GST-MLC1-N-t and GST-MLC1-C-t domains or the full length MLC1 recombinant protein (aa 2-377, FL) containing a Histidine (His) tag immobilized on glutation-agarose or Histidine-binding resin, respectively. The presence of CaMKII was observed in the pull-down assay performed with GST-MLC1-C-t and the FL protein, but not with the GSTMLC1-N-t (Fig. 3). The MLC1 GST-MLC1-C-t and FL protein also bound the serine/threonine phosphatases protein phosphatase 1 (PP1) and protein phosphatase 2A (PP2A), (Fig. 3), the most abundant serine-threonine phosphatases expressed in the brain that dephosphorylate CaM, CaMKII and their target proteins modulating their activity $[48,55]$. CaMKII and PP1/PP2A also bound WT MLC1 protein when pull-down experiments were performed using protein extracts derived from astrocytoma cells expressing WT (data not shown). Co-IF staining showed that CaMKII was expressed at very low levels in the cytosol of U251 cells in unstimulated conditions while it increased after cell treatments with hyposmotic and high $\mathrm{K}^{+}$solutions. In these latter conditions a partial colocalization with MLC1 was observed in perinuclear/ER areas (Fig. SD5 A-C).

\section{CaMKII phosphorylates MLC1 protein at the amino acid residue Threonine 17}

Since CaMKII is known to regulate the function of target proteins by their phosphorylation, we verified whether MLC1 that binds CaMKII was phosphorylated by this enzyme. To this aim, we carried 
out an in vitro kinase assay in the presence of $\left[\gamma^{32} \mathrm{P}\right]$ ATP using the MLC1 FL protein and the GSTMLC1 NH 2 -t as substrates for the CaMKII enzyme precipitated from U251 cells. The MLC1 N-terminal peptide was specifically chosen on the basis of the minimal aa recognition motif RXXS/T $[56,57]$ indicating a potential CaMKII target site in this protein end (the highly conserved aa sequence 1417, Fig. 4A). As shown in figure 4B, the immunoprecipitated phosphorylated (pCaMKII) enzyme was fully functional, being able to phosphorylate the MBP, a control substrate used to monitor CaMKII activity [58]. pCaMKII enzyme also phosphorylated the FL-MLC1 protein (Fig. 4C) and the MLC1-N-t peptide (Fig. 4D). The specificity of this phosphorylation was confirmed by introducing in the reaction mixture the CaMKII inhibitor KN93 [59] which strongly reduced MLC1 protein phosphorylation in both cases (Fig. 4C,D). Then, to identify exactly the aa residue targeted by the CaMKII enzyme, after the in vitro kinase assay performed with the use of the CaMKII recombinant enzyme, the GSTMLC1 NH 2 -t peptide was subjected to LC-MS/MS analysis. These experiments allowed the identification of a phosphorylation site at Threonine $(\mathrm{T})$ in position 17 of the $\mathrm{N}$-t peptide, within the supposed CaMKII consensus sequence RXXS/T (aa 14-17, Fig. 4E). We also tested whether MLC1 protein was a substrate of src, a kinase known to be expressed in astrocytes and involved in the control of volume changes $[60,61]$. The results of these latter experiments indicated that MLC1 was not phosphorylated by src (Fig. SD6).

\section{CaMKII phosphorylation of MLC1 increases protein stabilization at plasma membrane}

CaMKII phosphorylation of target proteins can strongly modulate their structural organization, intracellular localization and functionality. With the aim of clarifying the effects that CaMKII-mediated phosphorylation has on MLC1 structural and functional properties, we generated and characterized two U251 cell lines where the CaMKII phosphorylation site T17 was mutated i) into alanine (T17A), a not-phosphorylatable amino acid, or ii) into aspartic acid (T17D), an amino acid mimicking a constitutive phosphorylation. Characterization of these cell lines by WB and IF revealed that T17D substitution favored MLC1 dimers formation and increased MLC1 distribution at PM (and in some cells also in the cytosolic compartment), when compared to WT-MLC1 expressing cells (Fig. 5A,B, arrow and arrowheads, respectively). On the contrary, the not-phosphorylatable T17A mutation did not cause any consequences on MLC1 expression and localization (Fig. 5A,B). These latter results suggest that the CaMKII-mediated phosphorylation of MLC1 is not involved in MLC1 protein transport 
towards the PM, leaving unexplained the mechanism favoring MLC1 dimer formation and its increased localization at PM observed in cells expressing the T17D mutant. Since MLC1 protein localization at PM is the result of a combination of events such as protein transport towards PM, stabilization/maintenance at this location and endocytosis for protein recycling or degradation (Brignone et al., 2014), we verified whether the increased dimer formation and localization at PM of the MLC1 T17D mutant was due to PM protein stabilization and inhibition of its endocytosis/degradation. To clarify these mechanisms, we treated cells with cycloheximide (CHX), an inhibitor of protein biosynthesis [62], for different time lengths and verified by WB the degradation kinetics of the MLC1-T17D mutant in comparison with the MLC1-WT protein. These experiments indicated that T17D mutation improved MLC1 stability at PM, being the mutant protein still detectable after 4-5 $\mathrm{h}$ of $\mathrm{CHX}$ treatment, a time period when the WT MLC1 was already degraded (Fig. 5C). With these analyses, we confirmed that CaMKII-dependent phosphorylation of MLC1 stabilized the protein at PM by inhibiting its endocytosis/degradation. 
MLC1 activates VRAC-mediated $\mathrm{I}_{\mathrm{Cl}, \text { swell }}$ in Xenopus oocytes and U251 cells

The above findings revealed that CaMKII-mediated phosphorylation of MLC1 at T17 increased MLC1 dimer formation and protein stabilization at PM. We then hypothesized that this effect can also influence MLC1 functionality. Although MLC1 proper function is still unknown, its involvement in the activation of $\mathrm{Cl}^{-}$currents and cell volume regulation have been demonstrated in several MLC disease models. Thus, to assess the role of CaMKII phosphorylation on MLC1 functionality, we performed an electrophysiological characterization of astrocytoma cells expressing MLC1-WT or mutants to study whether the phosphorylation reported above affects MLC1 function, and in particular the amplitude of the MLC1-induced IClswell. First, to optimize the experimental conditions and confirm the ability of MLC1 to activate Iclswell we measured them in Xenopus ooctyes. In vitro transcribed mRNA encoding the MLC1 WT protein (Fig. SD7, A) was microinjected into oocytes and two-electrode voltage-clamp recordings were performed in control condition and during the application of the hyposmotic solution to activate the endogenously expressed I Ilswell (Fig. SD7, A). These recordings showed that the expression of MLC1 WT in oocytes enhanced the amplitude of $I_{\text {Clswell }}$ compared to control not-injected oocytes (Fig. SD7,B-F). Furthermore, the expression of the mutated MLC1S280L, which causes the complete loss of function of MLC1 protein, validated the specificity of the effect observed in addition to its pathophysiological role.

We then performed patch-clamp recordings on U251 control cells (transfected with the empty vector; Scr), and U251 expressing MLC1-WT or the mutated MLC1-S280L. Step potentials from -100 to $+100 \mathrm{mV}$ were imposed before (left) and during (center) perfusion with hyposmotic solution; the current resulting current obtained by subtracting the current elicited under Hypo solution and that in control condition is shown on the right. The quantitative analysis of these experiments showed that the hyposmosis-induced $\mathrm{ICl}_{\mathrm{l}, \text { swell }}$ density was significantly larger in MLC1-WT than both Scr and MLC1-S280L cells (Fig. 6A-C). Noteworthy, the expression of MLC1-WT also affected the inactivation kinetics and rectification degree of VRAC, further corroborating the ability of this protein to act as a VRAC modulator (Fig. 6D,E). Overall, these results indicated that MLC1 exerts important actions on VRAC activity and validated U251 as suitable cell models to test the effect of the $\mathrm{Ca}^{2+} / \mathrm{CaMKII}^{-m e d i-}$ ated phosphorylation on MLC1-induced VRAC currents.

\section{CaMKII phosphorylation potentiates MLC1-induced activation of VRAC currents}


Once we determined that the expression of a functional MLC1 in U251 cells was essential for the enhancement of the $\mathrm{I}_{\mathrm{Cl}, \text { swell }}$ mediated by VRAC, we investigated if the CaMKII-dependent phosphorylation of MLC1 represented a key step for its activation and the consequent modulation of $\mathrm{I}_{\mathrm{Cl}, \text { swell }}$ by MLC1 assessing the $\mathrm{I}_{\mathrm{Cl}, \text { swell }}$ density in U251 cells expressing MLC1 WT or carrying T17A or T17D mutations. In these cells, patch-clamp experiments in whole cell configuration were performed using voltage ramps from -100 to $+100 \mathrm{mV}$ from a holding potential of $-40 \mathrm{mV}$ (Fig. 7A). In Fig. 7A we illustrate the protocol used and the time course of the putative $I_{\mathrm{Cl} \text {, swell }}$ activation in $U 251$ cells by the hypotonic solution, together with representative current ramps (Inset: left) under hypotonic condi-

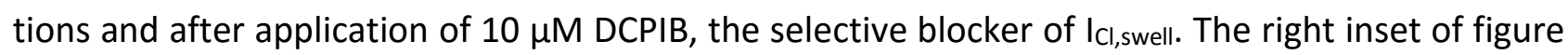
A shows typical $\mathrm{I}_{\mathrm{Cl}, \text { swell }}$ currents induced by step potentials during hyposmotic solution perfusion in the absence and presence of $10 \mu \mathrm{M}$ DCPIB, which fully blocked the hyposmosis-activated currents. Results from these experiments revealed that a significant increase of the inward current at $-80 \mathrm{mV}$ due to application of the hyposmotic solution occurred in all cell models, as shown in the bar plot of Fig. 7B. As described above, MLC1-WT cells exhibited a greater current density ( $54 \mathrm{pA} / \mathrm{pF}$ ) than cells transfected with the empty vector (Scr, not containing MLC1) ( 32 pA/pF). By analyzing the two cell populations harboring the mutation in the CaMKII phosphorylation site (T17D and T17A) we observed that the T17D cells, where MLC1 is constitutively phosphorylated, exhibited $\mathrm{I}_{\mathrm{Cl} \text {,swell }}$ density similar to WT cells ( $\sim 56 \mathrm{pA} / \mathrm{pF})$, while the current density observed in T17A cells ( $32 \mathrm{pA} / \mathrm{pF})$, where T17 in MLC1 cannot be phosphorylated, was similar to Scr cells. These results suggest that CaMKII phosphorylation of MLC1 is required for upregulating ICl,swell. In support of this view, we showed that $10 \mu \mathrm{M}$ of the CaMKII inhibitor KN93, acutely added to hyposmotic solution, was able to reduce $\mathrm{I}_{\mathrm{Cl}, \text { swell }}$ by $\sim 40 \%$ in WT cells (Fig. 7C). Notably, this was about the same difference between ICl,swell recorded in Scr and WT or between T17D and T17A.

Hyposmosis induces $\mathrm{Ca}^{2+}$ influx and $\mathrm{Ca}^{2+}$ release in $\mathrm{U} 251$ cells: role of extracellular $\mathrm{Ca}^{2+}$ influx in CaMKII/MLC1-dependent enhancement of VRAC

It is known that CaMKII is activated by CaM upon increase of cytosolic $\mathrm{Ca}^{2+}$. Increased cytosolic $\mathrm{Ca}^{2+}$ due to cell swelling has also been shown to activate $I_{C l, s w e l l}$ in astrocytes $[63,64]$. These results identify $\mathrm{Ca}^{2+}$ as a key player in the activation pathways of both MLC1 and ICl,swell. Since specific $\mathrm{Ca}^{2+}$ sources are known to be linked to specific functions and to differently influence MLC1 traf- 
ficking, we asked whether $\mathrm{Ca}^{2+}$ influx and/or $\mathrm{Ca}^{2+}$ release were important for the CaMKII/MLC1-dependent enhancement of the hyposmosis-induced $\mathrm{I}_{\mathrm{Cl}}$,swell. To distinguish between the contribution of $\mathrm{Ca}^{2+}$ influx and $\mathrm{Ca}^{2+}$ release from internal stores in the hyposmosis-induced $\mathrm{Ca}^{2+}$ movements in U251 cell lines, we carried out Fura-2-based fluorescence $\mathrm{Ca}^{2+}$ recording experiments. A hypoosmotic challenge lasting 15 min was imposed to Fura-2-loaded MLC1-WT cells in two different conditions (Fig. SD8 A,B). When control solution (containing $2.5 \mathrm{mM} \mathrm{Ca}^{2+}$ ) was used, most cells responded with a fast $\mathrm{Ca}^{2+}$ raise (peaking at one minute), very variable in amplitude. A slow raise of $\mathrm{Ca}^{2+}$ followed the initial peak, varying in both speed of onset and amplitude. On the other hand, a very simple response was recorded in $\mathrm{Ca}^{2+}$-free solution, in that the initial peak was completely absent and only a slow raising phase with similar onset rate and amplitude was observed. We can conclude that the first peak of $\mathrm{Ca}^{2+}$ was mainly due to $\mathrm{Ca}^{2+}$ entry, though we cannot rule out the presence also of $\mathrm{Ca}^{2+}$ release induced by $\mathrm{Ca}^{2+}$ entry (so called $\mathrm{CICR}$ ), which, instead, was most likely predominant in a later phase and represented by the asynchronous $\mathrm{Ca}^{2+}$ transients. Finally, the slowly raising phase recorded in $0-\mathrm{Ca}^{2+}$ depicts a homogeneous response among cells due to release from unidentified intracellular stores, not attributable to a CICR mechanism.

Once ascertained that the hypotonic stimulus triggered both $\mathrm{Ca}^{2+}$ influx and $\mathrm{Ca}^{2+}$ release from intracellular stores in our U251 cells, we asked if changes in cytosolic $\mathrm{Ca}^{2+}$ levels were important for the CaMKII/MLC1-dependent enhancement of $\mathrm{I}_{\mathrm{Cl}, \text { swell. }}$. We first carried out patch-clamp experiments aimed at distinguishing between the specific contribute of the two $\mathrm{Ca}^{2+}$ sources. To study the role of $\mathrm{Ca}^{2+}$ influx, after a stabilization period in $\mathrm{O}-\mathrm{Ca}^{2+}$ isotonic solution, cells were exposed to hyposmotic solution, still in the absence of external $\mathrm{Ca}^{2+}$, to assess the amount of $\mathrm{I}_{\mathrm{Cl}, \text { swell }}$ activated by cell swelling without the contribution of $\mathrm{Ca}^{2+}$ influx from outside. After a stable $\mathrm{I}_{\mathrm{cl} \text {,swell }}$ activation was reached, cells were probed with the same hypotonic solution containing $2 \mathrm{mM} \mathrm{Ca}^{2+}$, to evaluate the possible further increase of the current, due to the entry of external $\mathrm{Ca}^{2+}$ (Fig. 8A). The results obtained showed that only in WT-MLC1 expressing cells the $\mathrm{I}_{\mathrm{Cl}, \text { swell }}$ activated by the $\mathrm{Ca}^{2+}{ }^{2}$-free hypotonic solution was further increased (by 30\%) upon addition of external $\mathrm{Ca}^{2+}$, while in all the other cell types (Scr, T17D, and T17A) the current density remained virtually unchanged (Fig. 8B). Figure 8A illustrates a typical experiment carried out inMLC1-WT cells, showing the increment of $\mathrm{I}_{\mathrm{Cl}, \text { swell }}$ upon the addition of the hypotonic solution with $2 \mathrm{mM} \mathrm{Ca}^{2+}$. Similar tests were carried out with $0-\mathrm{Ca}^{2+}$ and with $2 \mathrm{mM} \mathrm{Ca}^{2+}$ in the activating hyposmotic solution, but this time tested in separate WT cell groups. In this case, we found the hyposmosis-activated $\mathrm{I}_{\mathrm{Cl}, \text { swell }}$ in the cell group probed in the presence of extracellular $\mathrm{Ca}^{2+}(\sim 54 \mathrm{pA} / \mathrm{pF})$ was about $70 \%$ larger than that elicited in the cell group 
probed in the absence of extracellular $\mathrm{Ca}^{2+}(\sim 32 \mathrm{pA} / \mathrm{pF})$ (Fig. $\left.8 \mathrm{C}\right)$. The reason of this quantitative difference was further investigated, and it could be attributed to the different experimental protocol used. Overall, the above results suggest that additional activation of $\mathrm{I}_{\mathrm{Cl}, \text { swell }}$ by external $\mathrm{Ca}^{2+}$ influx occurs only where MLC1 activity can be modulated by $\mathrm{Ca}^{2+}$ influx, which is the one major feature that differentiates WT from all the other cell lines here analyzed (Scr had virtually no MLC1, T17A cells had MLC1 that cannot be phosphorylated by the CamKII, and MLC1 in T17D cells wass always fully phosphorylated).

\section{CaMKII/MLC1-dependent enhancement of $I_{C l, \text { swell }}$ requires release of $\mathrm{Ca}^{2+}$ from intracellular stores} induced by extracellular $\mathrm{Ca}^{2+}$ influx

Previous studies using fluorescent dyes have shown that hyposmosis-induced cell swelling can trigger the release of $\mathrm{Ca}^{2+}$ from intracellular stores in astrocytes [65]. The above experiments using Fura-2 indicated that hyposmosis induced $\mathrm{Ca}^{2+}$ release in $\mathrm{U} 251$ even in the absence of $\mathrm{Ca}^{2+}$ influx (see $0-\mathrm{Ca}^{2+}$ experiments), without excluding however the possibility of $\mathrm{Ca}^{2+}$ influx-induced $\mathrm{Ca}^{2+}$ release $(\mathrm{CICR})$ mechanism. Since MLC1 protein activation at PM occurred in response to $\mathrm{Ca}^{2+}$ release from internal stores, we asked whether this $\mathrm{Ca}^{2+}$ was also involved in the CaMKII/MLC1-dependent enhancement of $\mathrm{I}_{\mathrm{Cl}, \text { swell. }}$. To answer this question, we assessed the maximal $\mathrm{I}_{\mathrm{Cl} \text {,swell }}$ activated by hypotonic solution with $0-\mathrm{Ca}^{2+}$ (to avoid contamination from external $\mathrm{Ca}^{2+}$ influx) in control MLC1-WT cells and in the same cells pretreated for 5 min with $1 \mu \mathrm{M}$ TG (i.e., with internal stores fully depleted). A representative experiment carried out in WT cells pretreated with TG, where the hypotonic solution with $0-\mathrm{Ca}^{2+}$ activated an inward current is shown in Fig. 9A. As control, the same protocol was applied on WT cells not pretreated with TG. The cumulative data, presented in panel B, showed that the $\mathrm{I}_{\mathrm{Cl}, \text { swell }}$ density was about 15\% lower in TG-pretreated cells, although the difference between the two groups was not statistically significant. As the influx of $\mathrm{Ca}^{2+}$ from extracellular space is able to further activate the $\mathrm{I}_{\mathrm{Cl} \text {,swell }}$ in WT cells (Fig. 8), we then asked whether $\mathrm{Ca}^{2+}$ entering into the cells could enhance directly the Icl,swell via the CaMKII/MLC1 pathway, or instead by stimulating the release of $\mathrm{Ca}^{2+}$ from the intracellular store via CICR. To understand if the CIRC-dependent source of intracellular $\mathrm{Ca}^{2+}$ from internal stores is important for the CaMKII/MLC1-dependent enhancement of $\mathrm{I}_{\mathrm{Cl}, \text { swell, }}$ we assessed the $\mathrm{I}_{\mathrm{Cl}, \text { swell }}$ density activated by hypotonic solution in $0-\mathrm{Ca}^{2+}$, in WT cells pre-treated or not with TG, and verified if an incremental $\mathrm{I}_{\mathrm{Cl}, \text { swell }}$ density could be observed upon switching on hypotonic solution with $2 \mathrm{mM} \mathrm{Ca}^{2+}$ (Fig. 9C; i.e., we followed the same logic of the 
experiment shown in Fig. 8). The analysis of the average fractional $\mathrm{I}_{\mathrm{Cl}}$,swell revealed that only in control WT cells not treated with TG the $\mathrm{I}_{\mathrm{Cl}, \text { swell }}$ activated by the $\mathrm{Ca}^{2+}$-free hypotonic solution was further increased (by $~ 30 \%$ ) upon addition of external $\mathrm{Ca}^{2+}$, while in TG-treated WT cells the current density remained unchanged (Fig. 9C).

This result indicated that when the internal stores are fully depleted of $\mathrm{Ca}^{2+}, \mathrm{Ca}^{2+}$ influx is ineffective

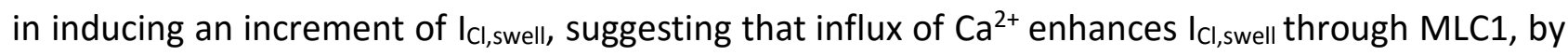
activating the CICR mechanism in cell expressing the CaMKII phosphorylatable MLC1 protein. 


\section{Discussion}

With the aim of increasing the knowledge of MLC disease molecular mechanisms and MLC1 protein role in the human brain, in this study we have explored for the first time the possibility that MLC1 functions are connected to $\mathrm{Ca}^{2+}$ signaling in astrocytes. In support of this hypothesis, a growing number of suggestive observations have emerged. We previously reported the localization of MLC1 in the lipid rafts [30], the PM microdomains that operate as $\mathrm{Ca}^{2+}$ signal transduction platforms where the clustering of $\mathrm{Ca}^{2+}$ channels, receptors, transporters and their regulators occurs to modulate $\mathrm{Ca}^{2+}$ mediated cellular functions $[66,67]$. Interestingly, all the MLC1 molecular interactors identified so far are transmembrane proteins structurally linked to raft compartments, including proteins involved in Iclswell and cell volume regulation (VRAC, CIC2, AQP4, KiR4.1) and EGFR-signaling pathway components, suggesting that $\mathrm{Ca}^{2+}$ signaling may exert some regulatory action on MLC1 functions. Indeed, previous observations reported that $\mathrm{Ca}^{2+}$ entry through voltage-dependent $\mathrm{Ca}^{2+}$ channels in response to cell depolarization causes the assembly of the MLC1/GlialCAM/CIC2 functional complex at the PM [68]. If the above data indicate a possible $\mathrm{Ca}^{2+}$-mediated regulation of MLC1 functions, the reported cooperation between MLC1 and the $\mathrm{Ca}^{2+}$ channel TRPV4 to favor $\mathrm{Ca}^{2+}$ entry in response to hyposmotic stress [30] support the concept that MLC1 itself could influence $\mathrm{Ca}^{2+}$ homeostasis in astrocytes. Consistent with these latter results, $\mathrm{Ca}^{2+}$ influx following hyposmotic and ATP stimulation was found impaired in monocytes/macrophages derived from MLC patients [27]. Overall, these findings converge on the idea of a reciprocal regulation between intracellular $\mathrm{Ca}^{2+}$ and MLC1 functions, prompting us to elucidate further these mechanisms.

Intracellular $\mathrm{Ca}^{2+}$ release, CaM binding and CaMKII-mediated phosphorylation affect MLC1 protein dimerization and plasma membrane trafficking and stabilization

Results here presented showed that MLC1 assembly and trafficking, two parameters indicating MLC1 functional activation, are differently regulated by $\mathrm{Ca}^{2+}$ influx or release, with $\mathrm{ER} \mathrm{Ca}^{2+}$ release, and not external $\mathrm{Ca}^{2+}$ influx, being capable of promoting MLC1 accumulation at the PM and acquisition of the dimeric/active form. ER is a dynamic $\mathrm{Ca}^{2+}$ store, acting as a signaling organelle that integrates different types of extra- and intracellular signals [69]. Due to the pumping activity of the SERCA, the ER is able to accumulate large amounts of $\mathrm{Ca}^{2+}$ (ranging 0.2-1.0 mM), generating a large $\mathrm{Ca}^{2+}$ gradient (four orders of magnitude) between the ER lumen and the cytosol that is used as driving force for $\mathrm{Ca}^{2+}$ release following membrane receptor stimulation and opening of InsP3 receptors 
(InsP3R). These cytosolic $\mathrm{Ca}^{2+}$ fluctuations act as signaling events that, by activating all the machinery of $\mathrm{Ca}^{2+}$-regulated signaling pathways and effector proteins (including CaM and CaMKII), allow to connect extracellular stimulations to intracellular molecular events [70 and reference therein]. Noteworthy, in astrocytes $\mathrm{Ca}^{2+}$ signaling induced by $\mathrm{ER} \mathrm{Ca}^{2+}$ release governs fundamental cellular processes like neurotransmitter and ion uptake/release, exocytosis/endocytosis, cytoskeleton polymerization/rearrangement, vesicular trafficking and volume regulation [reviewed 70]. Our results showed that also MLC1 protein trafficking, assembly and functionality are regulated by ER $\mathrm{Ca}^{2+}$ signaling through the CaM/CamKII protein binding and the CaMKII-mediated phosphorylation. We further demonstrated that CaM binding stimulated MLC1 trafficking to the PM, being this translocation inhibited by cell treatment with the specific CaM antagonist calmidazolium. At odd with CaM involvement in MLC1 trafficking, phosphorylation by CaMKII did not influence protein export, as indicated by cell treatment with the CaMKII inhibitor KN93. However, protein degradation kinetics experiments, showed that the $\mathrm{Ca}^{2+}$-dependent CaMKII phosphorylation of MLC1 favors protein stabilization at PM. It is known that the translocation and maintenance of some receptors/channels at PM is the result of a combination of factors including exocytosis, PM stabilization and internalization [71]. As previously reported in cultured astrocytes [30, 72], most of MLC1 is localized at ER and endosomal compartments in control conditions and it mobilizes to the PM in response to stimuli, such as ion imbalance or inflammatory stress signals. The control of MLC1 trafficking by $\mathrm{Ca}^{2+} / \mathrm{CaM}$ is a new evidence that can have important implications for the comprehension of the temporal and spatial regulation of MLC1 function in response to physiological and pathological stimulations inducing $\mathrm{Ca}^{2+}$ release in astrocytes. A further aspect that should be considered regarding the importance of MLC1 trafficking regulation is that almost all the MLC1 mutants analyzed so far in heterologous cell systems do not traffic to the PM but are retained in the ER compartment [8, 30].

In addition, the coexisting binding of the PP1 and PP2A phosphatases at the MLC1 C-terminal is indicative that this protein is subjected to very dynamic phosphorylation/dephosphorylation events that can accurately regulate its functionality. PP1 and PP2A are the most abundant phosphatases expressed in the brain where they modulate the function of several $\mathrm{Ca}^{2+}$ effector proteins and ion channels, particularly in neuronal cells [55]. Further investigations will be required to unravel how PP1 and PP2A can affect MLC1 properties.

CaMKII-mediated phosphorylation of MLC1 confers $\mathrm{Ca}^{2+}$-dependence to VRAC activation 
Our studies on the functional implications of the CaMKII-mediated phosphorylation of MLC1 revealed the essential contribution of this $\mathrm{Ca}^{2+}$-induced post-translational modification on VRAC activation. VRAC is the channel mainly responsible for both $\mathrm{I}_{\mathrm{Cl}}$,swell and volume regulation following the swelling of several type of cells including astrocytes [73]. In response to a reduction of extracellular osmolarity, VRAC releases osmolytes such as taurine and glutamate and anions such as chloride thus changing the driving force of osmolarity and inducing an efflux of water, that allow cells to restore their original size $[74,75]$. Lack of functional MLC1 or GlialCAM reduces VRAC currents [1216]. Conversely, MLC1 overexpression increases VRAC currents [13]. We here demonstrated that also in oocytes and U251 cells, WT-MLC1, but not mutated MLC1 overexpression potentiates $\mathrm{I}_{\mathrm{Cl}, \text { swell }}$ by affecting their amplitude, inactivation kinetics and rectification degree, further corroborating the notion of MLC1 as a VRAC modulator and validating these cell systems as suitable models to study MLC1-induced VRAC modulation. The morphological-functional characterization of U251 cell lines expressing MLC1 mutants insensitive to CaMKII phosphorylation (17A) or permanently phosphorylated (T17D), demonstrated that this specific post-translational modification is essential for the MLC1-mediated increase of VRAC activation, thus conferring $\mathrm{Ca}^{2+}$ dependence to this channel that would be otherwise insensitive to $\mathrm{Ca}^{2+}$ ions in glioma cells [31]. The observation that in presence of external $\mathrm{Ca}^{2+} \mathrm{ICl}_{\mathrm{Cl}}$ swell is increased in MLC1-WT, but not in T17A or T17D mutants, is in accordance with the ability of a Ca ${ }^{2+}$ influx to promote CaMKII-dependent MLC1 phosphorylation only in MLC1-WT expressing cells. Moreover, the abolition of $\mathrm{Ca}^{2+}$ influx-mediated increase of $\mathrm{I}_{\mathrm{Cl}, \text { swell }}$ after pretreatment with TG, confirmed the involvement of internal $\mathrm{Ca}^{2+}$ stores in this process, presumably via activation of the CICR mechanism. As summarized in Fig. 10, our results are consistent with the following molecular events: 1) the induction of an initial $\mathrm{Ca}^{2+}$ influx by hypotonic cell swelling, most likely due to opening of $\mathrm{Ca}^{2+}$ channels (membrane stretch-activated channels including TRPV4 and others like voltage-dependent $\mathrm{Ca}^{2+}$ channels); 2) the triggering of a massive release of $\mathrm{Ca}^{2+}$ from intracellular stores through the CIRC mechanism; 3) the resulting CaM/CaMKII activation; 4) CaM/CaMKII-mediated phopshorylation of MLC1 and the consequent stimulation of its trafficking and stabilization at the PM and 5) MLC1-induced upregulation of VRAC currents. Since neither direct interaction nor co-localization have been found between MLC1 and VRAC protein components, it is conceivable that the MLC1 functional activation of VRAC may occur by means of other molecular elements or via indirect, MLC1-mediated, post-translation modifications of VRAC subunits, as previously observed (Elorza-Vidal et al., 2018). The modulation of VRAC by $\mathrm{Ca}^{2+}$ is still an open issue. It 
has been generally assumed that VRAC is activated by a decrease of intracellular ion strength, following exposure to hyposmotic stress, a process where changes of intracellular $\mathrm{Ca}^{2+}$ can have a significant role depending on the cells analyzed [31,63, 76-78], although the underlying mechanism is still not understood. These apparent discrepancies may be attributed to several reasons, ranging from cell-specific properties of VRAC to the interaction (or not) of the channel with $\mathrm{Ca}^{2+}$-sensitive effectors. However, the importance of $\mathrm{Ca}^{2+}$ signaling in both VRAC activation and volume regulation has been reported in astrocytes where these channels play a key role in both physiological and pathological conditions. Indeed, in astrocytes VRAC can be activated by neurotransmitters and neuromodulators and also by extracellular ATP through the raise of intracellular $\mathrm{Ca}^{2+}$ levels, and PKC and CaM/CaMKII pathway activation. However, these studies leave unresolved the mechanism by which PKC and CaM/CaMKII activate VRAC $[79,80]$. Noteworthy, the results obtained in primary astrocytes are consistent with our data on U251 cells expressing MLC1, suggesting that ATP induces the increase of cytosolic $\mathrm{Ca}^{2+}$ thus promoting MLC1 dimerization and stabilization at the PM via the CaM/CaMKII pathway, and eventually leading to VRAC activation. Since the presence of a phosphor-

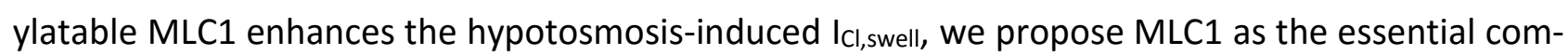
ponent for the $\mathrm{Ca}^{2+}$-dependent modulation of VRAC in astrocytes. This notion is further supported by the fact that in astrocytoma/glioblastoma cells, where MLC1 is virtually absent (or very low expressed), changes in intracellular $\mathrm{Ca}^{2+}$, or the activation/inhibition of PKC does not affect the kinetic, biophysical properties and amplitude of $\mathrm{I}_{\mathrm{Cl}, \text { swell }}[31,32]$. However, in non-tumor astrocytes where MLC1 is highly expressed, the $\mathrm{Ca}^{2+}$-modulation of the $\mathrm{I}_{\mathrm{Cl}, \text { swell }}$ was reported. It would be then plausible to assume that other similar proteins may replace MLC1 in providing $\mathrm{Ca}^{2+}$-sensitivity to VRAC in other cell types where the $\mathrm{Ca}^{2+}$ dependence of $\mathrm{I}_{\mathrm{Cl}, \text { swell }}$ has been demonstrated. Future studies will be necessary to elucidate this aspect.

\section{Significance of astrocyte $\mathrm{Ca}^{2+}$ signaling in MLC pathogenesis}

Data here presented revealed that in astrocytes MLC1 protein function is regulated by $\mathrm{Ca}^{2+}$ changes occurring in response to osmotic stress. Interestingly, in different in vitro and in vivo models, osmotic stress has been found to elicit robust $\mathrm{Ca}^{2+}$ responses in astrocyte end-feet, the brain tissue compartment where MLC1 is preferentially expressed [81]. In light of these findings, we can hypothesize that this osmotic stress-induced $\mathrm{Ca}^{2+}$ influx followed by $\mathrm{ER} \mathrm{Ca}^{2+}$ release in perivascular astrocyte end-feet leads to MLC1 activation and VRAC/TRPV4 potentiation to stimulate an efficient RVD. Alterations of these processes may cause abnormal astrocyte end-feet swelling resulting in BBB dysfunctions. In addition, since adjacent astrocytes are connected among them via $\mathrm{Ca}^{2+}$ permeable gap 
junctions forming the astrocyte syncytium [70], the CICR mechanism generates Ca2+ waves propagating along this astrocyte network $[70,82] . \mathrm{Ca}^{2+}$ wave spreading is known to modulate several fundamental astrocyte activities (i.e release/uptake of ions and gliotransmitters, support to BBB and NVU functionality) in both physiological and pathological conditions [83]. By potentiating TRPV4 and VRAC, and also by modulating the gap junction protein component Cx43 (Lanciotti et al., 2020), MLC1 might be itself involved in the control of $\mathrm{Ca}^{2+}$ wave diffusion along the astrocyte network. Indeed, VRAC has been found to favor $\mathrm{Ca}^{2+}$ propagation along the glial syncytium via extracellular ATP release [84]. It is worth noting that alterations of the $\mathrm{Ca}^{2+}$ signaling at the perivascular end-feet can cause serious consequences on NVU functionality since $\mathrm{Ca}^{2+}$ increase in this compartment adjusts cerebral blood flow during synaptic activity. Indeed it has been shown that electrical field stimulations in brain slices and in vivo inducing an increase in intracellular $\mathrm{Ca}^{2+}$ in perivascular astrocyte end-feet, followed by vascular smooth muscle $\mathrm{Ca}^{2+}$ oscillations and arteriolar dilation [85]. Thus, we cannot exclude that alterations of $\mathrm{Ca}^{2+}$ dynamics in astrocyte end-feet due to MLC1 mutations might indirectly influence arteriolar dilation and water permeability at the BBB causing edema and NVU dysfunctions. In accordance with this hypothesis, a recent study provide evidence of alterations of vascular smooth muscle cell contractility and NVU coupling in MLC1 KO mice [86].

\section{Concluding remarks}

Overall, these experiments indicate for the first time that MLC1 is a $\mathrm{Ca}^{2+}$-regulated protein that links volume regulation to $\mathrm{Ca}^{2+}$ dynamics in astrocytes. Further studies will be needed to fully understand the consequences of MLC1 mutation-induced dysfunctions of VRAC and volume regulation on NVU and BBB functions. Cell volume regulation is a very important process, particularly in the brain where it influences tissue excitability and function. For these reasons, the results here presented open new perspectives for the clarification of MLC pathogenesis and the comprehension of molecular events that are of interest for the identification of possible novel therapeutic targets for neurological conditions where astrocyte swelling and brain edema have a central role in the pathological process. 


\section{Figure Legends}

Figure 1. Effects of ionomycin (Iono), thapsigargin (TG) and ATP stimulation on MLC1 dimerization and translocation to the plasma membrane (PM) in U251 cells.

(A) WB analysis of U251 cell lines expressing MLC1 wild-type (MLC1-WT) shows a significant decrease of the MLC1 dimeric, PM-associated form (arrows) following lono treatment (15 min, $1 \mu \mathrm{M})$ when compared to untreated cells (CTRL). Panels C and E show upregulation of MLC1 dimers (arrows) following cell stimulation with TG (15 min, $100 \mathrm{nM})$ and ATP (5 min,100 $\mu \mathrm{M})$. MLC1 activation is not affected by co-treatment of TG or ATP with $100 \mu \mathrm{M}$ of Lanthanum Chloride ( $\mathrm{TG}+\mathrm{LaCl}_{3}$ and $\mathrm{ATP}+\mathrm{LaCl}_{3}$, in $\mathrm{C}$ and $\mathrm{E}$, respectively). Actin is used as a loading control. Molecular weight (MW) markers are indicated on the left $(\mathrm{kDa})$. The bar graphs represent the densitometry analysis of the MLC1 protein bands normalized with the amount of actin in the corresponding samples. The means +/SEM of three independent experiments are shown. Statistical differences were calculated using nonparametric tests $\left({ }^{*} p<0.05 ; * * p<0.01\right)$. IF stainings of U251 cells expressing MLC1-WT using antiMLC1 pAb (red) in combination with anti-Calnexin mAb (green) or FITC-conjugated phallacidin (green) show a decrease of MLC1 distribution at PM in lono treated cells (B), and an increase of PM localized MLC1 after cell treatment with TG (D) or ATP (F) when compared to untreated cells (CTRL). Scale bars: $20 \mu \mathrm{m}$.

Figure 2. Calmodulin (CaM) binds MLC1 protein $\mathrm{COOH}$ terminal and induces MLC1 protein trafficking to the PM in U251 cells expressing MLC1 WT

(A-B) schematic representation of MLC1 sequence showing the putative CaM binding consensus motif identified at the C-terminal domain of the MLC1 amino acid (aa) sequence (aa 323-339). (C) Pull-down assay using CaM-agarose resin and recombinant MLC1-NH $\mathrm{N}_{2}$ (aa 1-56) or MLC1-COOH (aa 320-377) terminal domains fused to glutation-S-transferase (GST-MLC1-N-t and GST-MLC1-C-t, respectively). WB analysis of the eluted proteins ( $f \times 1-3$ ) compared to the starting material (NL) shows that CaM/MLC1 binding occurs only with the GST-MLC1-C-t, and not with the GST-MLC1-N-t, as revealed by anti-GST antibody. (D) WB analysis of U251 cell expressing MLC1-WT shows a significant increase of the dimeric, PM-associated form of MLC1 (arrow) following a 15 min treatment with hyposmotic solution and a reduction after cell co-treatment with calmidazolium (CMZ) when compared to untreated cells. Actin is used as a loading control. MW markers are indicated on the left 
(kDa). The bar graphs represent the densitometry analysis of the MLC1 protein bands normalized with the amount of actin in the corresponding samples. The means +/-SEM of three-four independent experiments are shown. Statistical differences were calculated using non-parametric tests $\left({ }^{*} p<0.05\right)$. (E-G) IF stainings of U251 MLC1-WT cells by using anti-MLC1 pAb (red) in combination with anti-EEA1 mAb (green) show an increase of MLC1 expression after hyposmotic stimulation (F), and a lower localization of MLC1 at PM following cell co-treatment with CMZ (G) when compared to unstimulated conditions (CTRL,D). Scale bar: $20 \mu \mathrm{m}$.

Figure 3. CaMKII binds the $\mathrm{COOH}$ terminal of the MLC1 protein.

Pull-down assay of rat brain extract was performed using sepharose-immobilized GST-MLC1$\mathrm{NH}_{2}$ and $-\mathrm{COOH}$ terminal domains (GST-MLC1-N-t and GST-MLC1-C-t, respectively), and GST alone as control, along with agarose-immobilized Histidine (His)-fused MLC1 full length protein (HisMLC1-FL) and Histidines (His) alone as control. WB analysis of protein eluates reveals the binding of CaMKII, and of the phosphatase PP1 and PP2A to His-MLC1-FL and GST-MLC1-C-t but not to GSTMLC1-N-t. The starting material derived from rat brain extract is indicated as Input. MW markers are shown on the left $(\mathrm{kDa})$. One representative experiment out of two performed is shown.

Figure 4. CaMKII phosphorylates threonine 17 residue of the MLC1 protein.

(A) Schematic representation of MLC1 protein sequence showing a potential CaMKII target site in the N-terminal region of the MLC1 protein (aa 14-17). (B-D) In vitro kinase assay using CaMKII enzyme precipitated from U251 cells. The not-specific substrate MBP (B), the His-MLC1 full lenght pro-

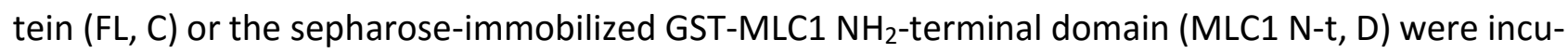
bated with the immunoprecipitated pCaMKII with or without KN93, a specific inhibitor of pCaMKII, and the reaction was carried out in the presence of $\left[\gamma^{32} \mathrm{P}\right]$ ATP. $\left[{ }^{32} \mathrm{P}\right]$-labeled proteins were revealed by autoradiography. (E) Mass spectrometry (MS) analysis of phosphorylated MLC1 $\mathrm{NH}_{2}$ terminal peptide after GluC digestion. In the upper part of the figure the sequence of GST-MLC1 NH2-terminal region is shown with MLC1-N-terminus highlighted in red. The lower panel shows the MS3 spectrum of the double charged phosphorylated peptide LAYDRMPTLE obtained after phosphoric acid loss caused by CID fragmentation. This neutral loss confirms the presence of a phosphorylated site and $b$ and $y$ series ions (reported in red and blue, respectively) in the MS3 spectrum localize the phosphorylation at T17. PT in the peptide sequence indicates a phosphorylated T, while a star marks the localization of the phospho $\mathrm{T}$ in the sequence of MLC1-N-terminal. 
Figure 5. CaMKII-mediated phosphorylation of the MLC1 T17 residue favors MLC1 protein dimerization and stabilization at PM.

Two U251 cell lines expressing MLC1 with specific substitutions of the T17 CaMKII phosphorylation site where generated and characterized. Threonine at position 17 was mutated into: 1) Alanine (T17A), a not phosphorylatable aa and 2) Aspartic acid (T17D), a phosphorylation mimicking aa. (A) WB analysis of U251 mutant cell lines shows that T17D substitution favors MLC1 dimeric formation (arrow) when compared to MLC1-WT and T17A expressing cells. Actin is used as a loading control. MW markers are indicated on the left $(\mathrm{kDa})$. The bar graphs represent the densitometry analysis of the MLC1 protein bands normalized with the amount of actin in the corresponding samples. The means + /-SEM of three independent experiments are shown. Statistical differences were calculated using non-parametric test ( $\left.{ }^{*} p<0.05\right)$. (B) IF staining of cells expressing MLC1-WT or T17A and T17D mutants by using anti-MLC1 pAb (red) and FITC-conjugated phallacidin (green) to stain actin filaments shows that T17D substitution increases MLC1 expression at PM and in intracellular compartments (arrowheads), when compared to MLC1-WT or T17A mutant expressing cells while no differences were observed in T17A expressing cells. Scale bars: $20 \mu \mathrm{m}$. (C) WB analysis of U251 cells expressing MLC1-WT or the T17D mutant, untreated (CTRL) or treated with cycloheximide (CHX, 100 $\mu \mathrm{g} / \mathrm{mL}$ ) for $1,3,4$ and $5 \mathrm{~h}$ reveals that the MLC1 T17D mutant is more stable than the MLC1-WT protein, being still detectable after 4 and $5 \mathrm{~h}$ of $\mathrm{CHX}$, when compared to the MLC1-WT protein, which disappears after $3 \mathrm{~h}$. Actin is used as a loading control. MW markers are indicated on the left (kDa). The bar graphs represent the densitometry analysis of the MLC1 protein bands normalized with the amount of actin in the corresponding samples. Data are expressed as percentage of the value measured in control untreated cells (considered as $100 \%$ ). Means \pm SEM of three experiments are shown. Statistical differences were calculated using non-parametric test $\left({ }^{*} p<0.05\right)$.

Figure 6. MLC1 up-regulates IClswell currents in U251 astrocytoma cells.

(A-C) Exemplificative I-V relationships recorded from -100 to $+100 \mathrm{mV}$ (Delta $=20 \mathrm{mV}$, Vholding -30 $\mathrm{mV}$; duration 1s) in U251 infected with an empty vector (Scr) (A), expressing WT MLC1 (B) or expressing the S280L MLC1 mutant(C) in control condition (left), following hyposmotic solution perfusion (middle) and after digital subtraction (Hypo-CTRL). (D,E) Mean I-V relationship of instantaneous and steady state current obtained in U251 control (black; n=6), MLC1 wt (red; n=9) and MLC1 S280L expressing cells (grey; $n=6$ ) after digital subtraction (Hypo-CTRL). 
Figure 7. Electrophysiological recording of $I_{C l, \text { swell }}$ currents in U251 cells.

(A) Representative time course of $\mathrm{I}_{\mathrm{Cl}, \text { swell }}$ density $(\mathrm{pA} / \mathrm{pF})$ measured from current ramps at $-80 \mathrm{mV}$, the equilibrium potential for $\mathrm{K}^{+}$under our recording conditions, during application of hypotonic solution (grey bar) and upon addition of $10 \mu \mathrm{M}$ DCPIB (green bar). Insets: Left, representative current ramps from -100 to $100 \mathrm{mV}$ (600 ms duration) from a holding potential of $-40 \mathrm{mV}$, under hypotonic solution (grey trace) and hypotonic solution containing $10 \mu \mathrm{M}$ DCPIB (green trace); Right, families of current traces evoked by applying $1 \mathrm{~s}$ voltage steps from -100 to $120 \mathrm{mV}$, in steps of $20 \mathrm{mV}$, from a holding potential of $-40 \mathrm{mV}$ in the presence of a hypotonic solution (grey traces), and in the presence of a hypotonic solution containing $10 \mu \mathrm{M}$ DCPIB (green traces). (B) Bar plot showing the average current density measured at $-80 \mathrm{mV}$ during exposure to $30 \%$ hypotonic solution, in cells transfected with empty vector ( $\mathrm{Ccr}, \mathrm{n}=10$ ) and U251 cells expressing a MLC1 WT protein (MLC1-WT, $n=14$ ) or two different MLC1 proteins carrying point mutations T17D (constitutive phosphorylated mutant, MLC1-T17D, n=9) or T17A (unphosphorylatable mutant, MLC1-T17A, n=14). (C) Bar plot showing the mean fractional $\mathrm{I}_{\mathrm{Cl}, \text { swell }}$ in presence of $10 \mu \mathrm{M} \mathrm{KN}-93(\mathrm{n}=3)$. Data are shown as mean $\pm \mathrm{SEM}$; $\mathrm{p}<0.05$; $* * p<0.01, * * * p<0.001$.

Figure 8. $I_{C l, \text { swell }}$ recording in presence and absence of extracellular $\mathrm{Ca}^{2+}$.

(A) Representative time course of $\mathrm{I}_{\mathrm{Cl}, \text { swell }}$ density during application of a $\mathrm{Ca}^{2+}$-free hypotonic solution (orange horizontal bar, Hypo $0 \mathrm{Ca}$ ) and a 30\% hypotonic solution containing $2 \mathrm{mM} \mathrm{Ca}^{2+}$ (grey horizontal bar, Hypo 2 Ca). (B) Bar plot showing the mean fractional $\mathrm{I}_{\mathrm{Cl}, \text { swell }}$ elicited by Hypo 30\%, as normalized on the current activated by hypotonic 0-Ca (dashed line), in Scr ( $n=7)$, MLC1-WT ( $n=7)$, MLC1-T17D ( $n=7)$ and MLC1-T17A ( $n=7)$ U251 cells. (C) Bar plot showing the average current density during exposure to hypotonic solution, in the continuous presence (grey bar) or absence (light green bar) of external $\mathrm{Ca}^{2+}$, assessed in MLC1-WT cells. Data are shown as mean $\pm \mathrm{SEM} ;{ }^{*} \mathrm{p}<0.01$.

Figure 9. ICl,swell recording in presence and absence of thapsigargin (TG)-induced $\mathrm{Ca}^{2+}$ store depletion.

(A) Representative time course of $\mathrm{ICl}$,swell density during application of a $\mathrm{Ca}^{2+}$-free hypotonic solution (orange bar, Hypo $0 \mathrm{Ca}$ ) and in succession of a hypotonic solution containing $2 \mathrm{mM} \mathrm{Ca}^{2+}$ (grey bar, hypo 2-Ca ${ }^{2+}$ ), in MLC1-WT cells in the presence of prior store depletion induced with $1 \mu \mathrm{M}$ TG pre-treatment. (B) Bar plot showing the average current density during exposure to hypotonic 0 
$\mathrm{Ca}^{2+}$ solution, in MLC1-WT cells in the absence (CTRL) and presence of TG pre-treatment (TG), measured at $-80 \mathrm{mV}$. Data are shown as mean $\pm \mathrm{SEM} ;{ }^{* *} \mathrm{p}<0.01$. (C) Bar plot showing the mean fractional ICl,swell elicited by Hypo 30\%, as normalized to the current activated by hypo0 $\mathrm{Ca}^{2+}$, in $\mathrm{MLC1}$ WT cells either in the absence or presence of TG.

Figure 10. Proposed molecular mechanisms of the $\mathrm{MLC1}$-induced $\mathrm{Ca}^{2+}$ regulation of VRAC.

1) Exposure to a hypotonic stress induces astrocyte (or astrocyte end-feet) swelling which triggers the opening of TRPV4 and other $\mathrm{Ca}^{2+}$ channels (voltage-dependent and mechanosensitive $\mathrm{Ca}^{2+}$ channels). 2) The entry of extracellular $\mathrm{Ca}^{2+}$ influx promotes $\mathrm{Ca}^{2+}$ release from the ER, likely mediated by the InsP3 (or/and Ryanodine) receptors, through the CICR mechanism. 3) The consequent elevation of intracellular $\mathrm{Ca}^{2+}$ is sensed by the $\mathrm{Ca}^{2+}$-binding protein calmodulin (CaM), which binds MLC1 favoring its trafficking to the PM and it activates the $\mathrm{Ca}^{2+} /$ calmodulin-dependent protein kinase II (CaMKII). 4) By phosphorylating the threonine aa at position 17 of the MLC1 protein (T17), CaMKII promotes MLC1 PM stabilization and its functional activation. 5) Phosphorylated MLC1 potentiates TRPV4 and VRAC channels favoring ICl,swell and regulatory volume decrease.

Figure SD1. Effects of ionomycin (Iono), thapsigargin (TG) and ATP stimulation on endogenous MLC1 protein expressed in primary mouse astrocytes.

(A-C) WB analysis performed on primary mouse astrocytes untreated (CTRL) or treated with lono (15 min, $1 \mu \mathrm{M}$; A), or TG (15 min, $100 \mathrm{nM}$; B) or ATP (5 min., $100 \mu \mathrm{M}$; C) shows a reduction of the MLC1 dimeric, PM associated form (arrows) after lono treatment and its increase following TG and ATP stimulations. TG and ATP treatments also induce an increase of the MLC1 monomeric form (asterisk in B and C, respectively). Actin is used as a loading control. MW markers are indicated on the left $(\mathrm{kDa})$. The bar graphs represent the densitometry analysis of the MLC1 protein bands normalized with the amount of actin in the corresponding samples. The means +/-SEM of three-four independent experiments are shown. Statistical differences were calculated using non-parametric tests $(* p<0.05 ; * * p<0.01)$.

Figure SD2. Effects of ionomycin (lono), thapsigargin (TG) and ATP stimulation on U251 cells expressing the MLC1 pathological mutant S280L.

(A-C) WB analysis performed on U251 cells expressing the MLC1-S280L mutant (MLC1-S280L) shows not significant differences in MLC1 protein expression/assembly after cell treatment with lono (15 
min, $1 \mu \mathrm{M}$; A), or TG (15 min, $100 \mathrm{nM}$; B) or ATP (5 min, $100 \mu \mathrm{M} ; \mathrm{C})$ when compared to untreated cells (CTRL). Actin is used as a loading control. MW markers are indicated on the left (kDa). The bar graphs represent the densitometry analysis of the MLC1 protein bands normalized with the amount of actin in the corresponding samples. The means +/-SEM of three independent experiments are shown. For statistical analyses, we performed non-parametric tests (ns, not significant).

Figure SD3. $\mathrm{Ca}^{2+}$ movements in U251 cells in response to treatments inducing MLC1 trafficking. To monitor the source of $\mathrm{Ca}^{2+}$ stimulating MLC1 trafficking changes, lono, TG and ATP were applied for 15 min to U251 cells expressing MLC1-WT. As depicted by the exemplifying Fura-2 $\mathrm{Ca}^{2+}$ recordings, TG (B) and ATP (C) induced $\mathrm{Ca}^{2+}$ transients due mainly to $\mathrm{Ca}^{2+}$ release from $\mathrm{ER}$ and $\mathrm{Ca}^{2+}$ entry from ER-depletion activated channels (capacitive $\mathrm{Ca}^{2+}$ entry, CCE). The application of the same agents in the presence of Lanthanum $\left(\mathrm{La}^{3+}\right)$ caused $\mathrm{Ca}^{2+}$ transients only due to release of the ion from ER, as expected. At odd, $\mathrm{Ca}^{2+}$ transient induced by lon (A) was mainly due to CCE-independent $\mathrm{Ca}^{2+}$ entry, and only slightly from $\mathrm{Ca}^{2+}$ release, as depicted from the transients recorded in 0$\mathrm{Ca}^{2+}$ or $\mathrm{La}^{3+}$. Traces are the mean of $\mathrm{Ca}^{2+}$ transients recorded from $\mathrm{n}=20-50$ cells.

Figure SD4. Colocalization of MLC1 and Calmodulin (CaM) in U251 cells expressing MLC1-WT (A-C) IF stainings using anti-CaM pAb (red) in combination with anti-MLC1 mAb (Xpress, green) show a very low level of CaM expression in the cytosolic compartment of U251 cells expressing MLC1-WT in unstimulated conditions (CTRL, A). Panel B and C reveal an increase of CaM expression and its partial colocalization with MLC1, mainly occurring into the perinuclear areas and ER, in U251 cells treated for 30 min with hyposmotic (hypo) and high $\mathrm{K}^{+}(\mathrm{HK})$ solutions (asterisks and arrowheads in $B, C$, respectively).

Figure SD5. Colocalization of MLC1 and CaMKII in U251 cells expressing MLC1-WT (A-C) IF stainings of U251 cells expressing MLC1-WT by using anti-pCaMKII pAb (red) in combination with anti-MLC1 mAb (Xpress, green) show low levels of pCaMKII expression in the cytosol of U251 cells (CTRL, A). An increase in pCaMKII expression and its partial colocalization with MLC1 was observed in the perinuclear areas and ER after cell treatment with hyposmotic and high $\mathrm{K}^{+}(\mathrm{HK})$ solutions for 30 min (asterisks and arrowheads in E and F, respectively). Scale bars: $20 \mu \mathrm{m}$.

Figure SD6. MLC1 protein was not phosphorylated by src kinase. 
In vitro phosphorylation assay to monitor the possible MLC1 protein phosphorylation by srckinase was performed using the His-MLC1 full-length protein (MLC1-FL, line 4), the sepharose-immobilized GST-MLC1 C-terminal and N-terminal domains (MLC1-C-t and MLC1-N-t, lines 5 and 6, respectively) and the non-specific substrate MBP (lanes 2 and 3). These peptides were incubated with the recombinant active src kinase. The first lane shows src alone as a control. The reaction was carried out in the presence of $\left[\gamma^{32} \mathrm{P}\right]$ ATP and $\left[{ }^{32} \mathrm{P}\right]$-labeled proteins were revealed by exposure to radiographic film. Src phosphorylated the MBP positive control (lanes 2,3) while no signal was detected in sample containing MLC1-FL, MLC1-C-t and MLC1-N-t (lanes 4-6). MW markers are shown on the left (kDa).

Figure SD7. MLC1 protein increases VRAC current activation in Xenopus oocytes.

(A) WB analysis of MLC1 expression in Xenopus oocytes injected with the indicated cRNAs revealed that maximum levels of MLC1 expression were observed $48 \mathrm{~h}$ after mRNA injection (day 2). MW markers are shown on the left $(\mathrm{kDa})$. (B-F) Two electrode voltage-clamp experiments were performed on uninjected and MLC1-WT or MLC1-S280L mutant injected oocytes. Families of voltage steps from -100 to $+100 \mathrm{mV}$ (20 mv intervals; HP -40 mV) were applied before (CTRL; left) and during hypotonic stimulation (Hypotonic; center). Hypotonic stimulation-induced currents were obtained by digital subtraction of CTRL currents from the currents recorded during Hypotonic stimulation (left). Panels E-F show the resulting IV curves calculated at the onset (Instantaneous) and at the end (Steady state) of the voltage steps. As depicted by the original currents and by the IV curves, the amplitude of hypotonic stimulation-induced anion currents is enhanced in MLC1-WT injected oocytes compared to MLC1-280L injected and control not-injected oocytes, in keeping with what observed in U251 cells.

Figure SD8. $\mathrm{Ca}^{2+}$ movements in U251 cells in response to hyposmotic stress Fura-2-loaded MLC1-WT expressing U251 cells were exposed to hyposmotic solution for 15 min in presence of $\mathrm{Ca}^{2+}(2.5 \mathrm{mM})$, or in a $0-\mathrm{Ca}^{2+}$ solution $\left(\mathrm{Ca}^{2+}\right.$ replaced by $\mathrm{Mg}^{2+}$ and with EGTA $\left.0.5 \mathrm{mM}\right)$. Exemplificative traces recorded in the presence $(A)$ or absence of $\mathrm{Ca}^{2+}(B)$ are shown. The amplitude of the $\mathrm{Ca}^{2+}$ peak was calculated as difference between the maximum value reached within the first $120 \mathrm{sec}$ of application of hyposmotic solution and the baseline value. Mean \pm SEM ( $n=27-29$ cells, from one experiment representative of 3 ) of the peak amplitudes were plotted in panel (C).

\section{References}


1. Bosch A, Estévez R (2020) Megalencephalic Leukoencephalopathy: Insights Into Pathophysiology and Perspectives for Therapy. Front Cell Neurosci 14:627887.

https://doi.org/10.3389/fncel.2020.627887

2. Teijido O, Martínez A, Pusch M, et al (2004) Localization and functional analyses of the MLC1 protein involved in megalencephalic leukoencephalopathy with subcortical cysts. Hum Mol Genet 13:2581-2594. https://doi.org/10.1093/hmg/ddh291

3. Boor PKI, de Groot K, Waisfisz Q, et al (2005) MLC1: a novel protein in distal astroglial processes. J Neuropathol Exp Neurol 64:412-419. https://doi.org/10.1093/jnen/64.5.412

4. Ambrosini E, Serafini B, Lanciotti A, et al (2008) Biochemical characterization of MLC1 protein in astrocytes and its association with the dystrophin-glycoprotein complex. Molecular and Cellular Neuroscience 37:480-493. https://doi.org/10.1016/j.mcn.2007.11.003

5. Hamilton EMC, Tekturk P, Cialdella F, et al (2018) Megalencephalic leukoencephalopathy with subcortical cysts: Characterization of disease variants. Neurology 90:e1395-e1403. https://doi.org/10.1212/WNL.0000000000005334

6. van der Knaap MS, Barth PG, Vrensen GF, Valk J (1996) Histopathology of an infantile-onset spongiform leukoencephalopathy with a discrepantly mild clinical course. Acta Neuropathol 92:206-212. https://doi.org/10.1007/s004010050510

7. Pascual-Castroviejo I, van der Knaap MS, Pronk JC, et al (2005) Vacuolating megalencephalic leukoencephalopathy: 24 year follow-up of two siblings. Neurologia 20:33-40

8. Duarri A, Lopez de Heredia M, Capdevila-Nortes X, et al (2011) Knockdown of MLC1 in primary astrocytes causes cell vacuolation: a MLC disease cell model. Neurobiol Dis 43:228238. https://doi.org/10.1016/j.nbd.2011.03.015

9. Topçu M, Gartioux C, Ribierre F, et al (2000) Vacuoliting megalencephalic leukoencephalopathy with subcortical cysts, mapped to chromosome 22qtel. Am J Hum Genet 66:733739. https://doi.org/10.1086/302758

10. Leegwater PA, Yuan BQ, van der Steen J, et al (2001) Mutations of MLC1 (KIAA0027), encoding a putative membrane protein, cause megalencephalic leukoencephalopathy with subcortical cysts. Am J Hum Genet 68:831-838. https://doi.org/10.1086/319519

11. López-Hernández T, Ridder MC, Montolio M, Capdevila-Nortes X, Polder E, Sirisi S, Duarri A, Schulte U, Fakler B, Nunes V, Scheper GC, Martínez A, Estévez R, van der Knaap MS. Mutant GlialCAM causes megalencephalic leukoencephalopathy with subcortical cysts, benign familial macrocephaly, and macrocephaly with retardation and autism. Am J Hum Genet. 2011 Apr 8;88(4):422-32. doi: 10.1016/j.ajhg.2011.02.009. Epub 2011 Mar 17. PMID: 21419380; PMCID: PMC3071909.

12. Ridder MC, Boor I, Lodder JC, et al (2011) Megalencephalic leucoencephalopathy with cysts: defect in chloride currents and cell volume regulation. Brain 134:3342-3354. https://doi.org/10.1093/brain/awr255 
13. Capdevila-Nortes X, López-Hernández T, Apaja PM, et al (2013) Insights into MLC pathogenesis: GlialCAM is an MLC1 chaperone required for proper activation of volume-regulated anion currents. Hum Mol Genet 22:4405-4416. https://doi.org/10.1093/hmg/ddt290

14. Sirisi S, Folgueira M, López-Hernández T, et al (2014) Megalencephalic leukoencephalopathy with subcortical cysts protein 1 regulates glial surface localization of GLIALCAM from fish to humans. Hum Mol Genet 23:5069-5086. https://doi.org/10.1093/hmg/ddu231

15. Hoegg-Beiler MB, Sirisi S, Orozco IJ, et al (2014) Disrupting MLC1 and GlialCAM and CIC-2 interactions in leukodystrophy entails glial chloride channel dysfunction. Nat Commun 5:3475. https://doi.org/10.1038/ncomms4475

16. Dubey M, Bugiani M, Ridder MC, et al (2015) Mice with megalencephalic leukoencephalopathy with cysts: a developmental angle. Ann Neurol 77:114-131.

https://doi.org/10.1002/ana.24307

17. Bugiani M, Dubey M, Breur M, et al (2017) Megalencephalic leukoencephalopathy with cysts: the Glialcam-null mouse model. Ann Clin Transl Neurol 4:450-465. https://doi.org/10.1002/acn3.405

18. Lanciotti A, Brignone MS, Visentin S, et al (2016) Megalencephalic leukoencephalopathy with subcortical cysts protein-1 regulates epidermal growth factor receptor signaling in astrocytes. Hum Mol Genet 25:1543-1558. https://doi.org/10.1093/hmg/ddw032

19. Elorza-Vidal X, Sirisi S, Gaitán-Peñas H, et al (2018) GlialCAM/MLC1 modulates LRRC8/VRAC currents in an indirect manner: Implications for megalencephalic leukoencephalopathy. Neurobiol Dis 119:88-99. https://doi.org/10.1016/j.nbd.2018.07.031

20. Brignone MS, Lanciotti A, Serafini B, et al (2019) Megalencephalic Leukoencephalopathy with Subcortical Cysts Protein-1 (MLC1) Counteracts Astrocyte Activation in Response to Inflammatory Signals. Mol Neurobiol 56:8237-8254. https://doi.org/10.1007/s12035-01901657-y

21. Brignone MS, Lanciotti $A$, Macioce $P$, et al (2011) The beta1 subunit of the Na,K-ATPase pump interacts with megalencephalic leucoencephalopathy with subcortical cysts protein 1 (MLC1) in brain astrocytes: new insights into MLC pathogenesis. Hum Mol Genet 20:90103. https://doi.org/10.1093/hmg/ddq435

22. Morita M, Higuchi C, Moto T, et al (2003) Dual regulation of calcium oscillation in astrocytes by growth factors and pro-inflammatory cytokines via the mitogen-activated protein kinase cascade. J Neurosci 23:10944-10952

23. Meini A, Sticozzi C, Massai L, Palmi M (2008) A nitric oxide/Ca(2+)/calmodulin/ERK1/2 mitogen-activated protein kinase pathway is involved in the mitogenic effect of IL-1beta in human astrocytoma cells. Br J Pharmacol 153:1706-1717.

https://doi.org/10.1038/bjp.2008.40 
24. Benfenati $V$, Caprini $M$, Dovizio $M$, et al (2011) An aquaporin-4/transient receptor potential vanilloid 4 (AQP4/TRPV4) complex is essential for cell-volume control in astrocytes. Proc Natl Acad Sci U S A 108:2563-2568. https://doi.org/10.1073/pnas.1012867108

25. Jo AO, Ryskamp DA, Phuong TTT, et al (2015) TRPV4 and AQP4 Channels Synergistically Regulate Cell Volume and Calcium Homeostasis in Retinal Müller Glia. J Neurosci 35:13525-13537. https://doi.org/10.1523/JNEUROSCI.1987-15.2015

26. Netti V, Fernández J, Kalstein M, et al (2017) TRPV4 Contributes to Resting Membrane Potential in Retinal Müller Cells: Implications in Cell Volume Regulation. J Cell Biochem 118:2302-2313. https://doi.org/10.1002/jcb.25884

27. Petrini S, Minnone G, Coccetti M, et al (2013) Monocytes and macrophages as biomarkers for the diagnosis of megalencephalic leukoencephalopathy with subcortical cysts. Mol Cell Neurosci 56:307-321. https://doi.org/10.1016/j.mcn.2013.07.001

28. Eleuteri C, Olla S, Veroni C, et al (2017) A staged screening of registered drugs highlights remyelinating drug candidates for clinical trials. Sci Rep 7:45780. https://doi.org/10.1038/srep45780

29. Calogero A, Lombari V, De Gregorio G, et al (2004) Inhibition of cell growth by EGR-1 in human primary cultures from malignant glioma. Cancer Cell Int 4:1. https://doi.org/10.1186/1475-2867-4-1

30. Lanciotti A, Brignone MS, Molinari P, et al (2012) Megalencephalic leukoencephalopathy with subcortical cysts protein 1 functionally cooperates with the TRPV4 cation channel to activate the response of astrocytes to osmotic stress: dysregulation by pathological mutations. Hum Mol Genet 21:2166-2180. https://doi.org/10.1093/hmg/dds032

31. Catacuzzeno L, Michelucci A, Sforna L, et al (2014) Identification of key signaling molecules involved in the activation of the swelling-activated chloride current in human glioblastoma cells. J Membr Biol 247:45-55. https://doi.org/10.1007/s00232-013-9609-9

32. Sforna L, Cenciarini M, Belia S, et al (2017) Hypoxia Modulates the Swelling-Activated Cl Current in Human Glioblastoma Cells: Role in Volume Regulation and Cell Survival. J Cell Physiol 232:91-100. https://doi.org/10.1002/jcp.25393

33. Arnedo T, López-Hernández T, Jeworutzki E, et al (2014) Functional analyses of mutations in HEPACAM causing megalencephalic leukoencephalopathy. Hum Mutat 35:1175-1178. https://doi.org/10.1002/humu.22622

34. Molinari P, Casella I, Costa T (2008) Functional complementation of high-efficiency resonance energy transfer: a new tool for the study of protein binding interactions in living cells. Biochem J 409:251-261. https://doi.org/10.1042/BJ20070803

35. Lanciotti A, Brignone MS, Camerini S, et al (2010) MLC1 trafficking and membrane expression in astrocytes: role of caveolin-1 and phosphorylation. Neurobiol Dis 37:581-595. https://doi.org/10.1016/j.nbd.2009.11.008 
36. Shevchenko A, Wilm M, Vorm O, Mann M (1996) Mass spectrometric sequencing of proteins silver-stained polyacrylamide gels. Anal Chem 68:850-858.

https://doi.org/10.1021/ac950914h

37. Yates JR, Eng JK, McCormack AL, Schieltz D (1995) Method to correlate tandem mass spectra of modified peptides to amino acid sequences in the protein database. Anal Chem 67:1426-1436. https://doi.org/10.1021/ac00104a020

38. D'Adamo MC, Liu Z, Adelman JP, et al (1998) Episodic ataxia type-1 mutations in the hKv1.1 cytoplasmic pore region alter the gating properties of the channel. EMBO J 17:1200-1207. https://doi.org/10.1093/emboj/17.5.1200

39. López-Hernández T, Ridder MC, Montolio M, Capdevila-Nortes X, Polder E, Sirisi S, Duarri A, Schulte U, Fakler B, Nunes V, Scheper GC, Martínez A, Estévez R, van der Knaap MSMutant GlialCAM causes megalencephalic leukoencephalopathy with subcortical cysts, benign familial macrocephaly, and macrocephaly with retardation and autism.Am J Hum Genet. 2011 Apr 8;88(4):422-32. doi: 10.1016/j.ajhg.2011.02.009. Epub 2011 Mar 17PMID: 21419380

40. Hwang J, Park K, Lee G-Y, et al (2021) Transmembrane topology and oligomeric nature of an astrocytic membrane protein, MLC1. Open Biol 11:210103.

https://doi.org/10.1098/rsob.210103

41. Müller MS, Obel LF, Waagepetersen HS, et al (2013) Complex actions of ionomycin in cultured cerebellar astrocytes affecting both calcium-induced calcium release and store-operated calcium entry. Neurochem Res 38:1260-1265. https://doi.org/10.1007/s11064-0131021-4

42. Neary JT, Fu Q, Bender AS, Norenberg MD (1993) Effect of external acidosis on basal and ATP-evoked calcium influx in cultured astrocytes. Brain Res 604:211-216. https://doi.org/10.1016/0006-8993(93)90371-s

43. Pizzo P, Burgo A, Pozzan T, Fasolato C (2001) Role of capacitative calcium entry on glutamate-induced calcium influx in type-I rat cortical astrocytes. J Neurochem 79:98-109. https://doi.org/10.1046/j.1471-4159.2001.00539.x

44. Kovacs GG, Zsembery A, Anderson SJ, et al (2005) Changes in intracellular Ca2+ and pH in response to thapsigargin in human glioblastoma cells and normal astrocytes. Am J Physiol Cell Physiol 289:C361-371. https://doi.org/10.1152/ajpcell.00280.2004

45. Brignone MS, Lanciotti A, Visentin S, et al (2014) Megalencephalic leukoencephalopathy with subcortical cysts protein-1 modulates endosomal $\mathrm{pH}$ and protein trafficking in astrocytes: relevance to MLC disease pathogenesis. Neurobiol Dis 66:1-18. https://doi.org/10.1016/j.nbd.2014.02.003

46. Kawasaki H, Kretsinger RH (1995) Calcium-binding proteins 1: EF-hands. Protein Profile 2:297-490 
47. Urrutia J, Aguado A, Muguruza-Montero A, Núñez E, Malo C, Casis O, Villarroel A. The Crossroad of Ion Channels and Calmodulin in Disease. Int J Mol Sci. 2019 Jan 18;20(2):400. doi: 10.3390/ijms20020400. PMID: 30669290; PMCID: PMC6359610.

48. Swulius MT, Waxham MN (2008) $\mathrm{Ca}(2+) /$ calmodulin-dependent protein kinases. Cell Mol Life Sci 65:2637-2657. https://doi.org/10.1007/s00018-008-8086-2

49. Scemes E, Spray DC (2012) Extracellular $\mathrm{K}^{+}$and astrocyte signaling via connexin and pannexin channels. Neurochem Res 37:2310-2316. https://doi.org/10.1007/s11064-012-07594

50. Fischer R, Schliess F, Häussinger D (1997) Characterization of the hypo-osmolarity-induced $\mathrm{Ca} 2+$ response in cultured rat astrocytes. Glia 20:51-58

51. Sirisi S, Elorza-Vidal X, Arnedo T, et al (2017) Depolarization causes the formation of a ternary complex between GlialCAM, MLC1 and CIC-2 in astrocytes: implications in megalencephalic leukoencephalopathy. Hum Mol Genet 26:2436-2450.

https://doi.org/10.1093/hmg/ddx134

52. Etxeberria A, Aivar $P$, Rodriguez-Alfaro JA, et al (2008) Calmodulin regulates the trafficking of KCNQ2 potassium channels. FASEB J 22:1135-1143. https://doi.org/10.1096/fj.079712 com

53. Joiner WJ, Khanna R, Schlichter LC, Kaczmarek LK (2001) Calmodulin regulates assembly and trafficking of SK4/IK1 Ca2+-activated K+ channels. J Biol Chem 276:37980-37985. https://doi.org/10.1074/jbc.M104965200

54. Dagher $R$, Brière $C$, Fève $M$, et al (2009) Calcium fingerprints induced by calmodulin interactors in eukaryotic cells. Biochim Biophys Acta 1793:1068-1077. https://doi.org/10.1016/j.bbamcr.2008.11.019

55. Leslie SN, Nairn AC (2019) CAMP regulation of protein phosphatases PP1 and PP2A in brain. Biochim Biophys Acta Mol Cell Res 1866:64-73. https://doi.org/10.1016/j.bbamcr.2018.09.006

56. Kennelly PJ, Krebs EG (1991) Consensus sequences as substrate specificity determinants for protein kinases and protein phosphatases. J Biol Chem 266:15555-15558

57. Pearson RB, Kemp BE (1991) Protein kinase phosphorylation site sequences and consensus specificity motifs: tabulations. Methods Enzymol 200:62-81.

https://doi.org/10.1016/0076-6879(91)00127-i

58. Ishida A, Kameshita I, Fujisawa H (1998) A novel protein phosphatase that dephosphorylates and regulates Ca2+/calmodulin-dependent protein kinase II. J Biol Chem 273:19041910. https://doi.org/10.1074/jbc.273.4.1904

59. Wong MH, Samal AB, Lee M, et al (2019) The KN-93 Molecule Inhibits Calcium/CalmodulinDependent Protein Kinase II (CaMKII) Activity by Binding to Ca2+/CaM. J Mol Biol 431:1440-1459. https://doi.org/10.1016/j.jmb.2019.02.001 
60. Pomerance M, Gavaret JM, Breton M, Pierre M (1994) Growth factor-regulated phosphatidylinositol-3-kinase in astrocytes. Involvement of pp60c-src. Cell Mol Biol (Noisy-le-grand) 40:653-664

61. Okada Y, Sato K, Numata T (2009) Pathophysiology and puzzles of the volume-sensitive outwardly rectifying anion channel. J Physiol 587:2141-2149.

https://doi.org/10.1113/jphysiol.2008.165076

62. Kao S-H, Wang W-L, Chen C-Y, et al (2015) Analysis of Protein Stability by the Cycloheximide Chase Assay. Bio Protoc 5:e1374. https://doi.org/10.21769/BioProtoc.1374

63. Liu Y, Zhang $\mathrm{H}$, Men $\mathrm{H}$, et al (2019) Volume-regulated $\mathrm{Cl}$ - current: contributions of distinct $\mathrm{Cl}$ - channels and localized Ca2+ signals. Am J Physiol Cell Physiol 317:C466-C480. https://doi.org/10.1152/ajpcell.00507.2018

64. Mola MG, Saracino E, Formaggio F, et al (2021) Cell Volume Regulation Mechanisms in Differentiated Astrocytes. Cell Physiol Biochem 55:196-212.

https://doi.org/10.33594/000000469

65. O'Connor ER, Kimelberg HK (1993) Role of calcium in astrocyte volume regulation and in the release of ions and amino acids. J Neurosci 13:2638-2650

66. Weerth SH, Holtzclaw LA, Russell JT (2007) Signaling proteins in raft-like microdomains are essential for Ca2+ wave propagation in glial cells. Cell Calcium 41:155-167.

https://doi.org/10.1016/j.ceca.2006.06.006

67. Pani B, Singh BB (2009) Lipid rafts/caveolae as microdomains of calcium signaling. Cell Calcium 45:625-633. https://doi.org/10.1016/i.ceca.2009.02.009

68. Sirisi S, Elorza-Vidal X, Arnedo T, Armand-Ugón M, Callejo G, Capdevila-Nortes X, LópezHernández T, Schulte U, Barrallo-Gimeno A, Nunes V, Gasull X, Estévez R. Depolarization causes the formation of a ternary complex between GlialCAM, MLC1 and CIC-2 in astrocytes: implications in megalencephalic leukoencephalopathy. Hum Mol Genet. $2017 \mathrm{Jul}$ 1;26(13):2436-2450. doi: 10.1093/hmg/ddx134. PMID: 28398517.

69. Li C, Qian T, He R, et al (2021) Endoplasmic Reticulum-Plasma Membrane Contact Sites: Regulators, Mechanisms, and Physiological Functions. Front Cell Dev Biol 9:627700. https://doi.org/10.3389/fcell.2021.627700

70. Lim D, Semyanov A, Genazzani A, Verkhratsky A (2021) Calcium signaling in neuroglia. In: International Review of Cell and Molecular Biology. Elsevier, pp 1-53

71. Ciappelloni S, Murphy-Royal C, Dupuis JP, et al (2017) Dynamics of surface neurotransmitter receptors and transporters in glial cells: Single molecule insights. Cell Calcium 67:46-52. https://doi.org/10.1016/j.ceca.2017.08.009

72. Lanciotti A, Brignone MS, Bertini E, Petrucci TC, Aloisi F, Ambrosini E.. ASTROCYTES: EMERGING STARS IN LEUKODYSTROPHY PATHOGENESIS.Transl Neurosci. 2013 Jun 1;4(2):10.2478/s13380-013-0118-1. doi: 10.2478/s13380-013-0118-1.PMID: 24340223 
73. Formaggio F, Saracino E, Mola MG, et al (2019) LRRC8A is essential for swelling-activated chloride current and for regulatory volume decrease in astrocytes. FASEB J 33:101-113. https://doi.org/10.1096/fj.201701397RR

74. Pasantes-Morales H, Lezama RA, Ramos-Mandujano G, Tuz KL (2006) Mechanisms of cell volume regulation in hypo-osmolality. Am J Med 119:S4-11. https://doi.org/10.1016/j.amjmed.2006.05.002

75. Jentsch TJ, Lutter D, Planells-Cases R, et al (2016) VRAC: molecular identification as LRRC8 heteromers with differential functions. Pflugers Arch 468:385-393.

https://doi.org/10.1007/s00424-015-1766-5

76. Akita T, Okada Y (2014) Characteristics and roles of the volume-sensitive outwardly rectifying (VSOR) anion channel in the central nervous system. Neuroscience 275:211-231. https://doi.org/10.1016/j.neuroscience.2014.06.015

77. Benedetto R, Sirianant L, Pankonien I, et al (2016) Relationship between TMEM16A/anoctamin 1 and LRRC8A. Pflugers Arch 468:1751-1763. https://doi.org/10.1007/s00424-0161862-1

78. Centeio R, Ousingsawat J, Schreiber R, Kunzelmann K (2020) Ca2+ Dependence of VolumeRegulated VRAC/LRRC8 and TMEM16A Cl- Channels. Front Cell Dev Biol 8:596879. https://doi.org/10.3389/fcell.2020.596879

79. Mongin AA, Kimelberg HK (2003) Is autocrine ATP release required for activation of volume-sensitive chloride channels? J Neurophysiol 90:2791-2792; author reply 2792-2793. https://doi.org/10.1152/jn.00615.2003

80. Mongin AA, Kimelberg HK (2005) ATP regulates anion channel-mediated organic osmolyte release from cultured rat astrocytes via multiple Ca2+-sensitive mechanisms. Am J Physiol Cell Physiol 288:C204-213. https://doi.org/10.1152/ajpcell.00330.2004

81. Eilert Olsen M, Hjukse JB, Thoren AE, et al (2019) Astroglial endfeet exhibit distinct $\mathrm{Ca}^{2+}$ signals during hypoosmotic conditions. Glia 67:2399-2409.

https://doi.org/10.1002/glia.23692

82. Denizot A, Arizono M, Nägerl UV, et al (2019) Simulation of calcium signaling in fine astrocytic processes: Effect of spatial properties on spontaneous activity. PLoS Comput Biol 15:e1006795. https://doi.org/10.1371/journal.pcbi.1006795

83. Verkhratsky A (2006) Glial calcium signaling in physiology and pathophysiology. Acta Pharmacol Sin 27:773-780. https://doi.org/10.1111/j.1745-7254.2006.00396.x

84. Fujii Y, Maekawa S, Morita M (2017) Astrocyte calcium waves propagate proximally by gap junction and distally by extracellular diffusion of ATP released from volume-regulated anion channels. Sci Rep 7:13115. https://doi.org/10.1038/s41598-017-13243-0

85. Lind $B L$, Jessen $S B$, Lønstrup $M$, et al (2018) Fast Ca2+ responses in astrocyte end-feet and neurovascular coupling in mice. Glia 66:348-358. https://doi.org/10.1002/glia.23246 
86. Gilbert $A$, ElorzaVidal $X$, Rancillac $A$, Chagnot $A$, Yetim $M$, Hingot $V$, Deffieux $T$, Boulay $A C, A$ Ivear-Perez R, Cisternino S, Martin S, Taïb S, 7, Gelot A, Mignon V, Favier M, Brunet I, Declèves X, Tanter M, Estevez R, Vivien D, Saubaméa B, Cohen-Salmon, Megalencephalic leukoencephalopathy with subcortical cysts is a developmental disorder of the gliovascular unit. M. Elife 2021 Nov 1;10:e71379. doi: 10.7554/eLife.71379. 


\section{Aknowledgments}

We thank Dr Antonella Calogero for providing us the U251 astrocytoma cell lines and Dr Cristina Agresti and Dr Alessia Formato for the preparation of mouse astrocyte cultures.

\section{Declarations}

Animals CD1 Swiss mice were purchased from Harlan Laboratories (San Pietro Al Natisone, Udine, Italy). The study was approved by the National Center for Animal Research and Welfare of the Istituto Superiore di Sanità and by the Italian Ministry of Health (Authorization 271/SSA/2010).

\section{Funding}

This work was supported by Italian Ministry of Health, Ricerca Finalizzata, (Grant N. GR-201302355882 to A.L.); European Leukodystrophies Association (ELA) (Grant N. ELA 2016-002F3 to E.A. and M.S.B) and 5x1000 project of the Istituto Superiore di Sanità (Project code: ISS5×1000_21949432e8c9be to A.L.).

\section{Conflicts of Interest}

The authors declare no conflict of interest. 



\section{Figures}
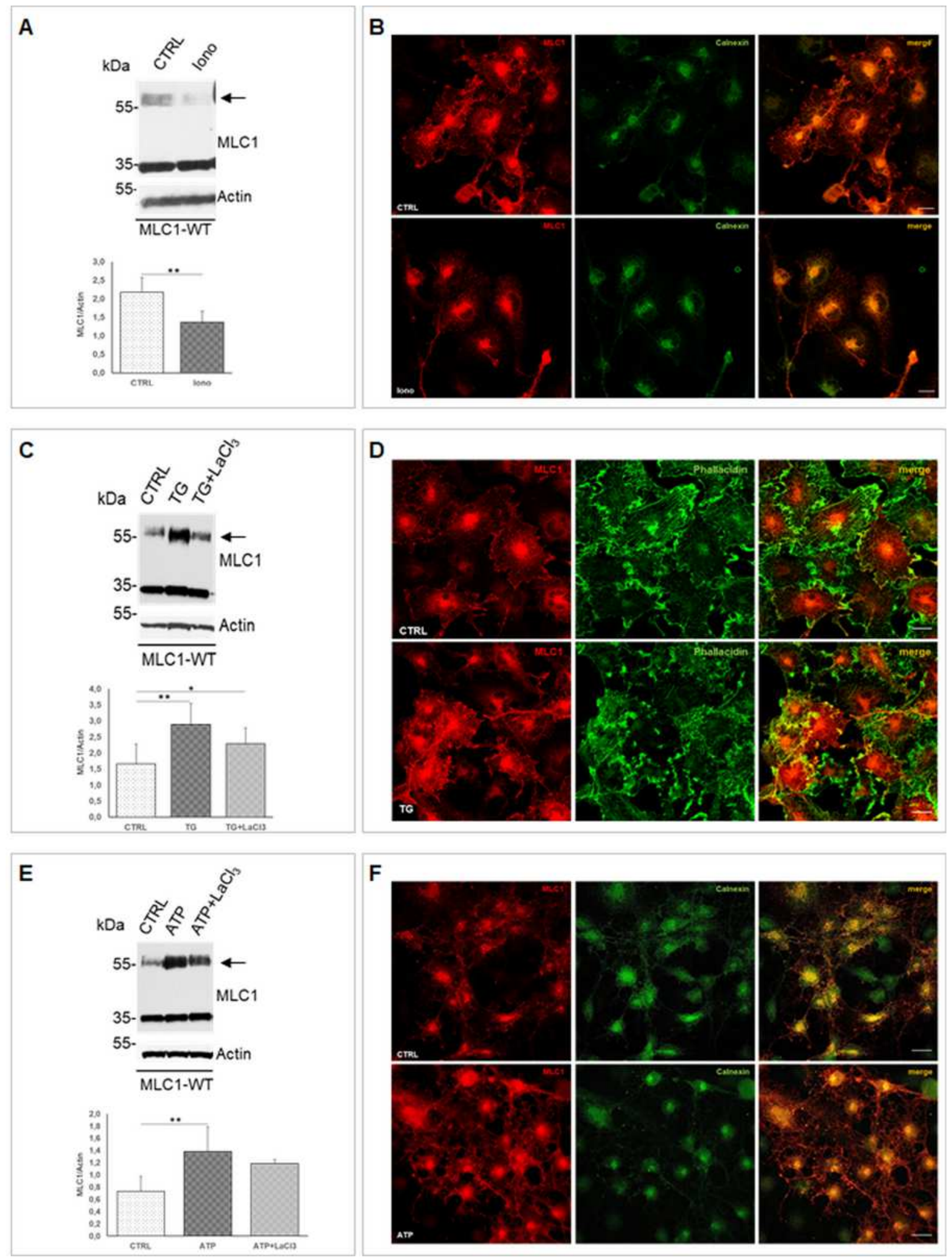

Figure 1

Effects of ionomycin (Iono), thapsigargin (TG) and ATP stimulation on MLC1 dimerization and translocation to the plasma membrane (PM) in U251 cells. (A) WB analysis of U251 cell lines expressing MLC1 wild-type (MLC1-WT) shows a significant decrease of the MLC1 dimeric, PM-associated form 
(arrows) following lono treatment $(15 \mathrm{~min}, 1 \mu \mathrm{M})$ when compared to untreated cells (CTRL). Panels $\mathrm{C}$ and E show upregulation of MLC1 dimers (arrows) following cell stimulation with TG (15 min, $100 \mathrm{nM}$ ) and ATP $(5$ min, $100 \mu \mathrm{M})$. MLC1 activation is not affected by co-treatment of TG or ATP with $100 \mu \mathrm{M}$ of Lanthanum Chloride ( $\mathrm{TG}+\mathrm{LaCl} 3$ and $\mathrm{ATP}+\mathrm{LaCl} 3$, in $\mathrm{C}$ and $\mathrm{E}$, respectively). Actin is used as a loading control. Molecular weight (MW) markers are indicated on the left $(\mathrm{kDa})$. The bar graphs represent the densitometry analysis of the MLC1 protein bands normalized with the amount of actin in the corresponding samples. The means +/- SEM ofthree independent experiments are shown. Statistical differences were calculated using nonparametric tests $\left({ }^{*} p<0.05 ;{ }^{*} p<0.01\right)$. IF stainings of U251 cells expressing MLC1-WT using antiMLC1 pAb (red) in combination with anti-Calnexin mAb (green) or FITCconjugated phallacidin (green) show a decrease of MLC1 distribution at PM in lono treated cells (B), and an increase of PM localized MLC1 after cell treatment with TG (D) or ATP (F) when compared to untreated cells (CTRL). Scale bars: $20 \mu \mathrm{m}$. 


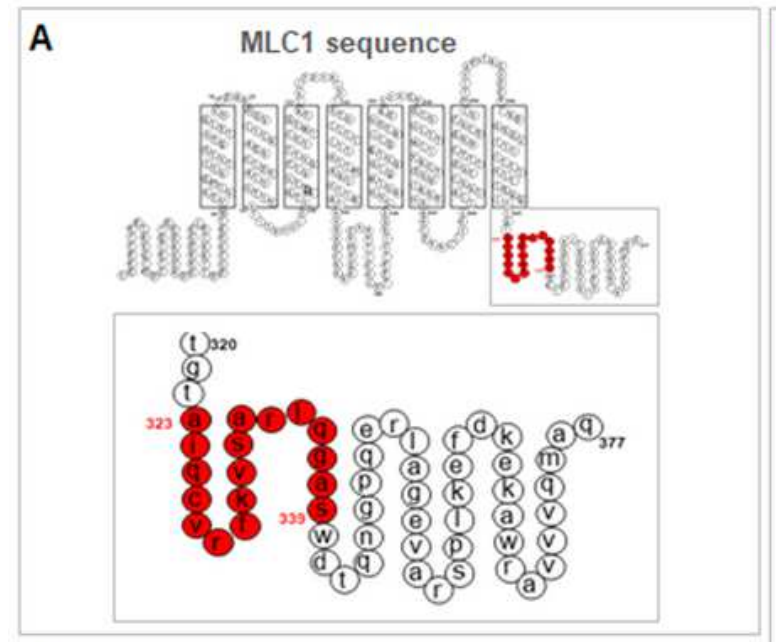

B

\section{CALMODULIN TARGET DATABASE}

http://calcium. uhnres. utoronto.ca/ctdb/ctdb/sequence.html

Minimum score for sequence: 0 Maximum score: 4

....1 MTQEPFREEL AYDRUPTLER GRCOPASYAD DAKPSOLQLS KRLPPCFSHK

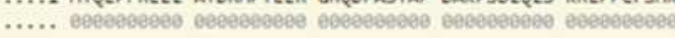

...51 TWWFSVLMGS CLLVTSGFSL YLGWFPAEM OYLRCAAGSC IPSAIVSFTV

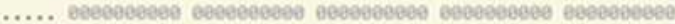

..101 SRRNAWIPN FQILFVSTFA VTITCLIWFG CKLVLNPSAI NINFNLILLL

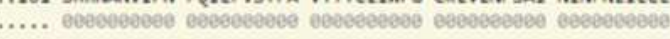
..251 LLELLMAATV IIAARSSEED CKKKKGSMSO SANILDEVPF PARVLKSYSV

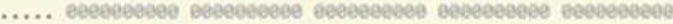

201 VEVIAGISAV LGGIIALNV DSVSGPHLSV TFFWILVACF PSAIASHVA

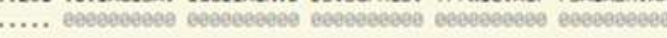
..2S1 ECPSKCLVEV LIAISSLTSP LLFTASGYSS FSIMRIVEMF KDYPPAIKPS

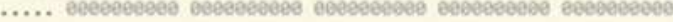
..381 YDVLLLLLLL VLLLQAGLNT GI IQCVRRK VSARLQGAGN DTQNGPQERL

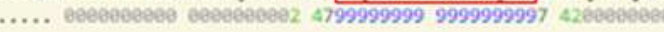
..351 AGEVARSPLK EFDKEKANRA WVQMAQ .....

$+t^{2}+2+4$

D
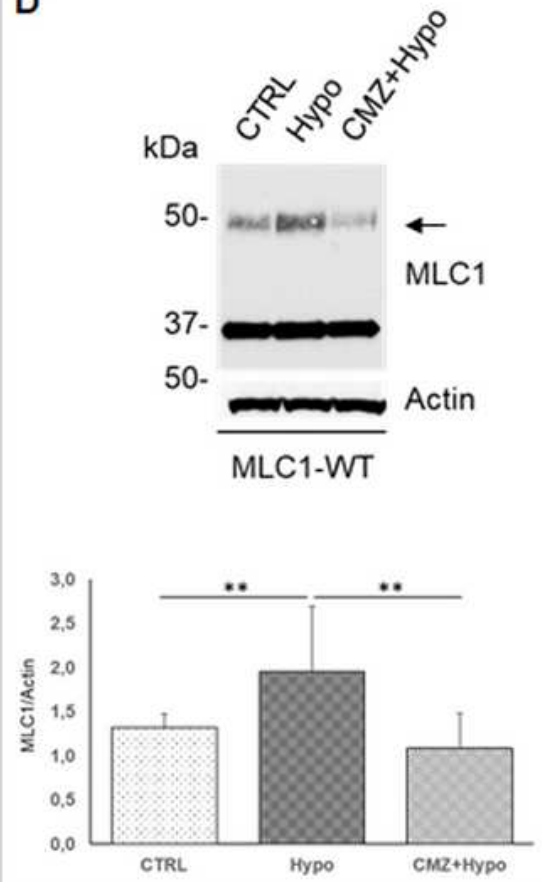
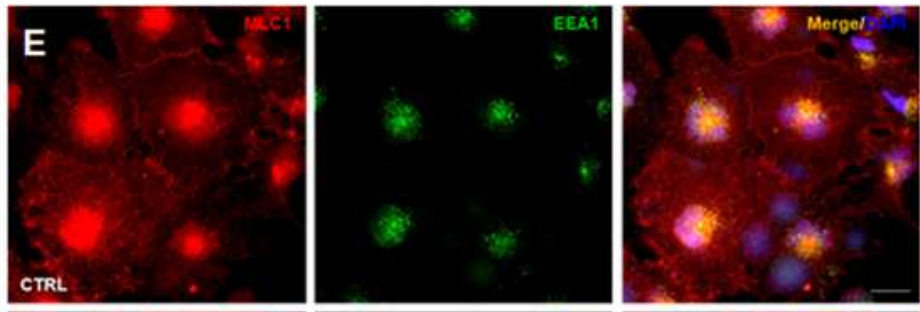

$\mathbf{F}$
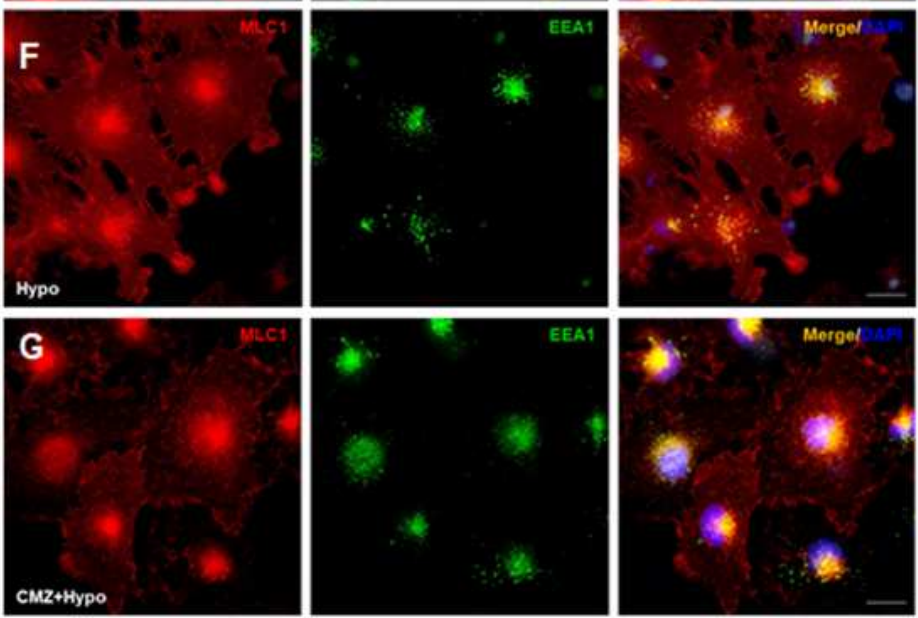

\section{Figure 2}

Calmodulin (CaM) binds MLC1 protein $\mathrm{COOH}$ terminal and induces MLC1 protein trafficking to the PM in U251 cells expressing MLC1 WT (A-B) schematic representation of MLC1 sequence showing the putative CaM binding consensus motif identified at the C-terminal domain of the MLC1 amino acid (aa) sequence (aa 323-339). (C) Pull-down assay using CaM-agarose resin and recombinant MLC1-NH2 (aa 1-56) or MLC1-COOH (aa 320-377) terminal domains fused to glutation-S-transferase (GST-MLC1-N-t and GST- 
MLC1-C-t, respectively). WB analysis of the eluted proteins ( $f \times 1-3)$ compared to the starting material (NL) shows that CaM/MLC1 binding occurs only with the GST-MLC1-C-t, and not with the GST-MLC1-N-t, as revealed by anti-GST antibody. (D) WB analysis of U251 cell expressing MLC1-WT shows a significant increase of the dimeric, PM-associated form of MLC1 (arrow) following a 15 min treatment with hyposmotic solution and a reduction after cell co-treatment with calmidazolium (CMZ) when compared to untreated cells. Actin is used as a loading control. MW markers are indicated on the left (kDa). The bar graphs represent the densitometry analysis of the MLC1 protein bands normalized with the amount of actin in the corresponding samples. The means +/-SEM of three-four independent experiments are shown. Statistical differences were calculated using non-parametric tests $\left({ }^{*} \mathrm{p}<0.05\right)$. (E-G) IF stainings of U251 MLC1-WT cells by using anti-MLC1 pAb (red) in combination with anti-EEA1 mAb (green) show an increase of MLC1 expression after hyposmotic stimulation (F), and a lower localization of MLC1 at PM following cell co-treatment with $\mathrm{CMZ}(\mathrm{G})$ when compared to unstimulated conditions (CTRL,D). Scale bar: $20 \mu \mathrm{m}$. 


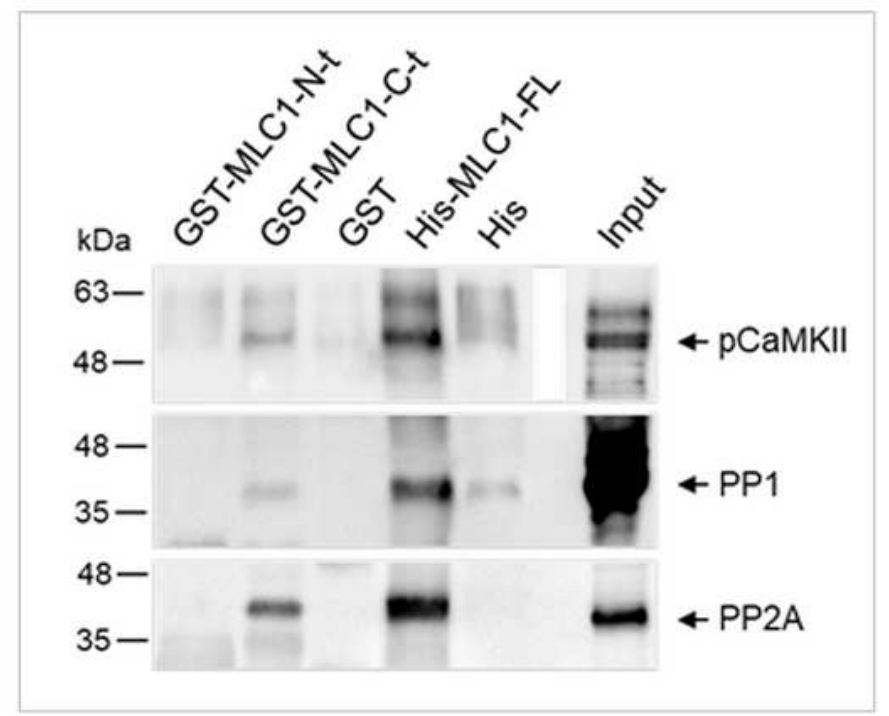

\section{Figure 3}

CaMKII binds the $\mathrm{COOH}$ terminal of the MLC1 protein. Pull-down assay of rat brain extract was performed using sepharose-immobilized GST-MLC1- NH2 and -COOH terminal domains (GST-MLC1-N-t and GSTMLC1-C-t, respectively), and GST alone as control, along with agarose-immobilized Histidine (His)-fused MLC1 full length protein (HisMLC1-FL) and Histidines (His) alone as control. WB analysis of protein eluates reveals the binding of CaMKII, and of the phosphatase PP1 and PP2A to His-MLC1-FL and GST- 
MLC1-C-t but not to GSTMLC1-N-t. The starting material derived from rat brain extract is indicated as Input. MW markers are shown on the left $(\mathrm{kDa})$. One representative experiment out of two performed is shown.

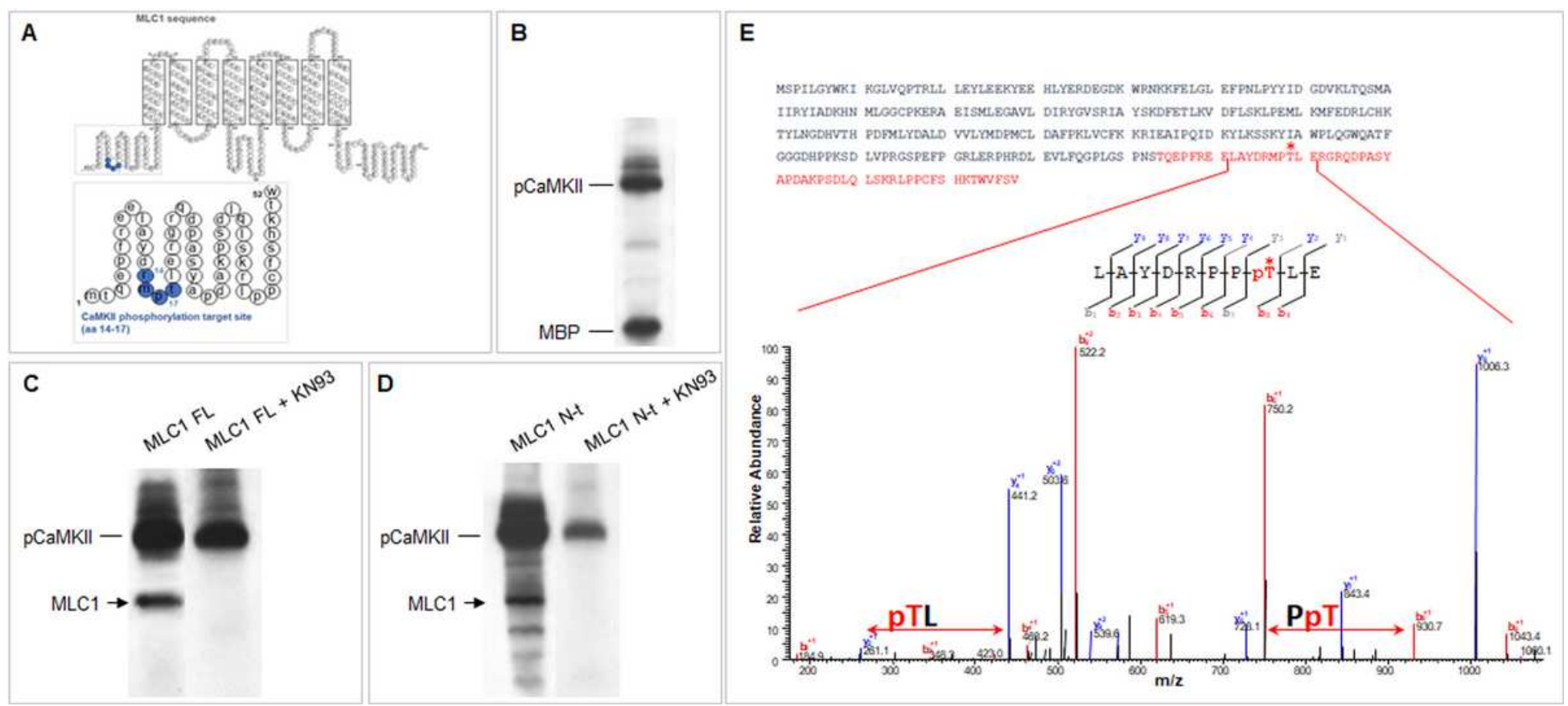

\section{Figure 4}

CaMKII phosphorylates threonine 17 residue of the MLC1 protein. (A) Schematic representation of MLC1 protein sequence showing a potential CaMKII target site in the N-terminal region of the MLC1 protein (aa 14-17). (B-D) In vitro kinase assay using CaMKII enzyme precipitated from U251 cells. The not-specific substrate MBP $(B)$, the His-MLC1 full lenght protein ( $F L, C)$ or the sepharose-immobilized GST-MLC1 NH2terminal domain (MLC1 N-t, D) were incubated with the immunoprecipitated pCaMKII with or without KN93, a specific inhibitor of pCaMKIl, and the reaction was carried out in the presence of [Y32P] ATP. [ 32P]-labeled proteins were revealed by autoradiography. (E) Mass spectrometry (MS) analysis of phosphorylated MLC1 NH2 terminal peptide after GluC digestion. In the upper part of the figure the sequence of GST-MLC1 NH2-terminal region is shown with MLC1-N-terminus highlighted in red. The lower panel shows the MS3 spectrum of the double charged phosphorylated peptide LAYDRMPTLE obtained after phosphoric acid loss caused by CID fragmentation. This neutral loss confirms the presence of a phosphorylated site and $b$ and y series ions (reported in red and blue, respectively) in the MS3 spectrum localize the phosphorylation at T17. PT in the peptide sequence indicates a phosphorylated T, while a star marks the localization of the phospho T in the sequence of MLC1-N-terminal. 


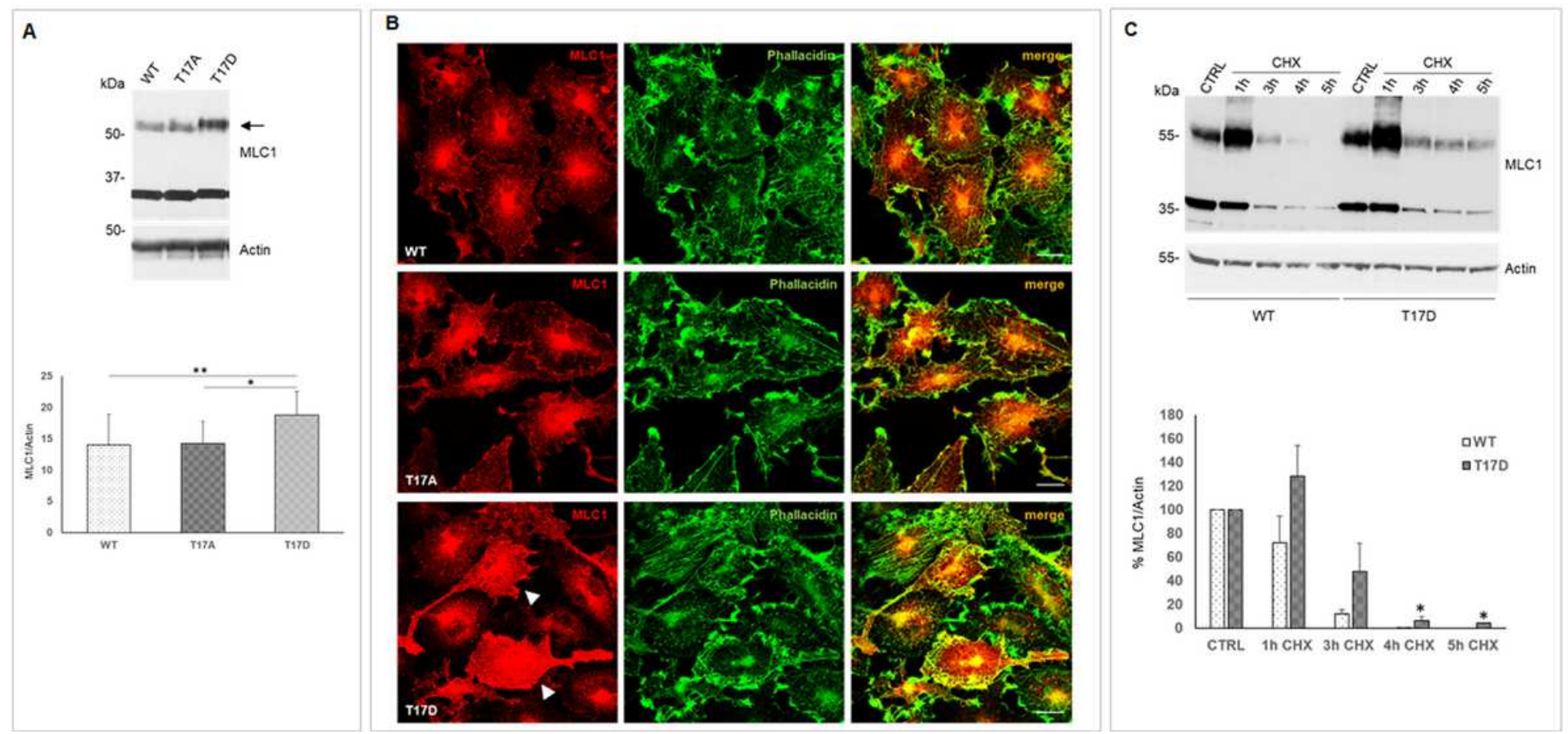

\section{Figure 5}

CaMKII-mediated phosphorylation of the MLC1 T17 residue favors MLC1 protein dimerization and stabilization at PM. Two U251 cell lines expressing MLC1 with specific substitutions of the T17 CaMKII phosphorylation site where generated and characterized. Threonine at position 17 was mutated into: 1) Alanine (T17A), a not phosphorylatable aa and 2) Aspartic acid (T17D), a phosphorylation mimicking aa. (A) WB analysis of U251 mutant cell lines shows that T17D substitution favors MLC1 dimeric formation (arrow) when compared to MLC1-WT and T17A expressing cells. Actin is used as a loading control. MW markers are indicated on the left $(\mathrm{kDa})$. The bar graphs represent the densitometry analysis of the MLC1 protein bands normalized with the amount of actin in the corresponding samples. The means +/-SEM of three independent experiments are shown. Statistical differences were calculated using non-parametric test ( $\left.{ }^{*} p<0.05\right)$. (B) IF staining of cells expressing MLC1-WT or T17A and T17D mutants by using antiMLC1 pAb (red) and FITC-conjugated phallacidin (green) to stain actin filaments shows that T17D substitution increases MLC1 expression at PM and in intracellular compartments (arrowheads), when compared to MLC1-WT or T17A mutant expressing cells while no differences were observed in T17A expressing cells. Scale bars: $20 \mu \mathrm{m}$. (C) WB analysis of U251 cells expressing MLC1-WT or the T17D mutant, untreated (CTRL) or treated with cycloheximide (CHX, $100 \mu \mathrm{g} / \mathrm{mL})$ for $1,3,4$ and $5 \mathrm{~h}$ reveals that the MLC1 T17D mutant is more stable than the MLC1-WT protein, being still detectable after 4 and $5 \mathrm{~h}$ of $\mathrm{CHX}$, when compared to the MLC1-WT protein, which disappears after $3 \mathrm{~h}$. Actin is used as a loading control. MW markers are indicated on the left $(\mathrm{kDa})$. The bar graphs represent the densitometry analysis of the MLC1 protein bands normalized with the amount of actin in the corresponding samples. Data are expressed as percentage of the value measured in control untreated cells (considered as $100 \%)$. Means \pm SEM of three experiments are shown. Statistical differences were calculated using non-parametric test $\left({ }^{*} p<0.05\right.$ 
A
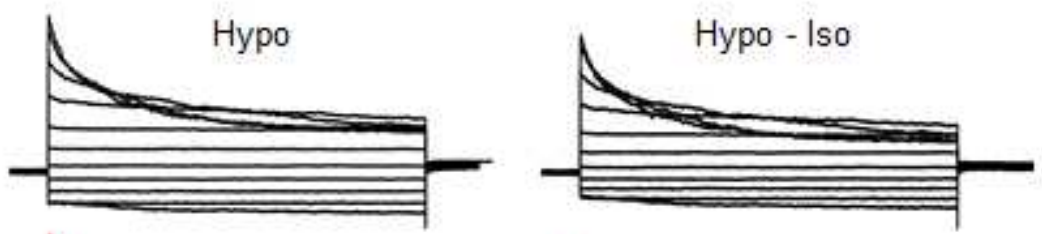

B
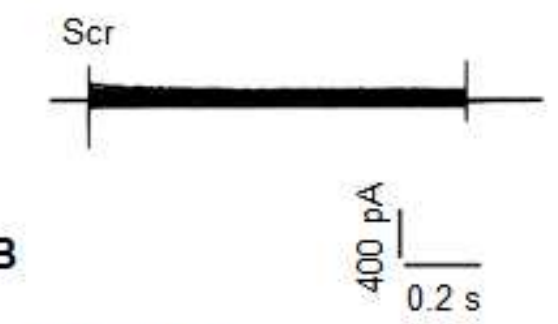

MLC1-WT
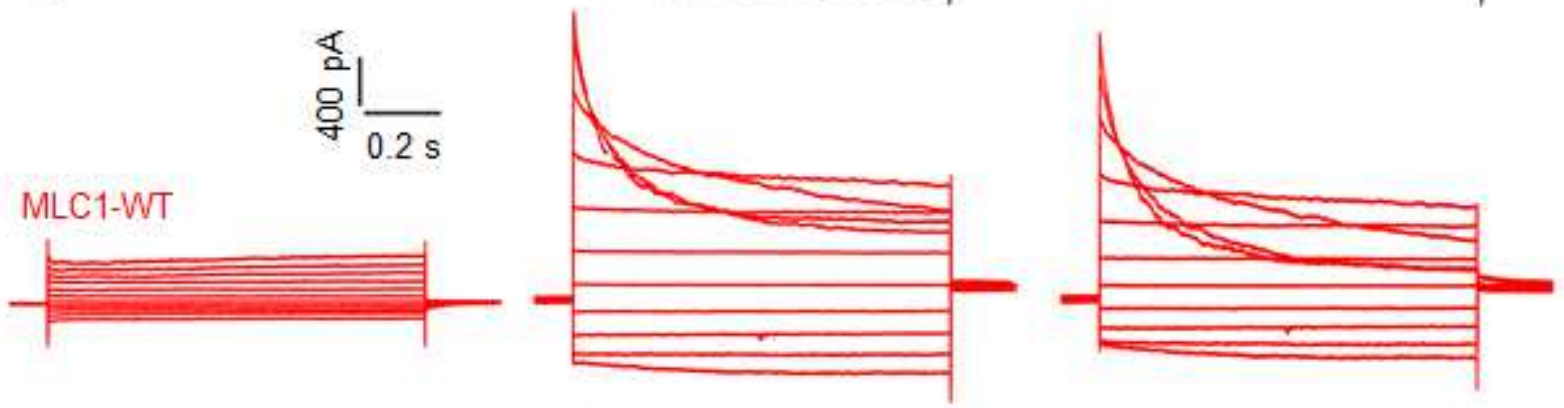

C

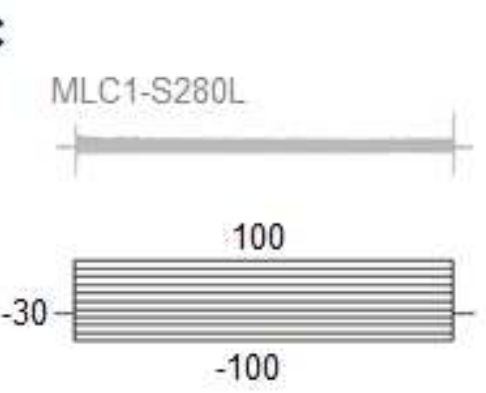

D
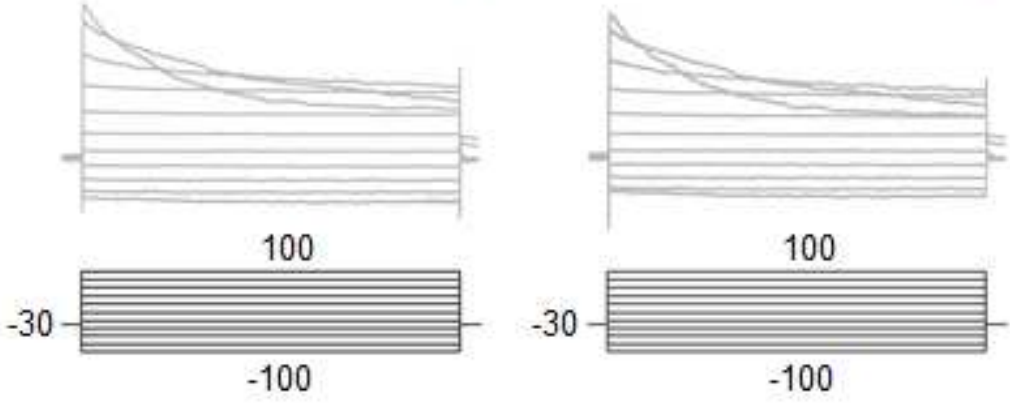

E
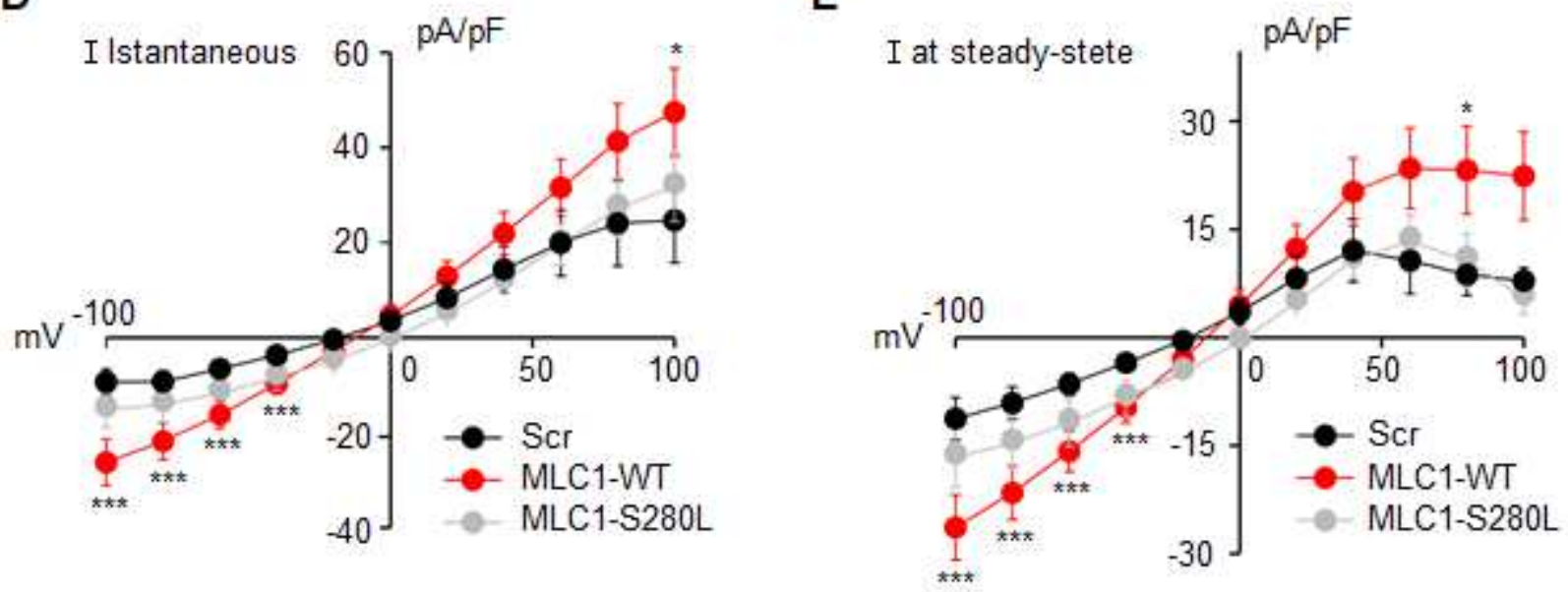

\section{Figure 6}

MLC1 up-regulates IClswell currents in U251 astrocytoma cells. (A-C) Exemplificative I-V relationships recorded from -100 to $+100 \mathrm{mV}$ (Delta $=20 \mathrm{mV}$, Vholding $-30 \mathrm{mV}$; duration $1 \mathrm{~s}$ ) in U251 infected with an empty vector (Scr) (A), expressing WT MLC1 (B) or expressing the S280L MLC1 mutant(C) in control condition (left), following hyposmotic solution perfusion (middle) and after digitalsubtraction (HypoCTRL). (D,E) Mean I-V relationship of instantaneous and steady state current obtained in U251 control (black; n=6), MLC1 wt (red; n=9) and MLC1 S280L expressing cells (grey; $n=6$ ) after digital subtraction (Hypo-CTRL). 


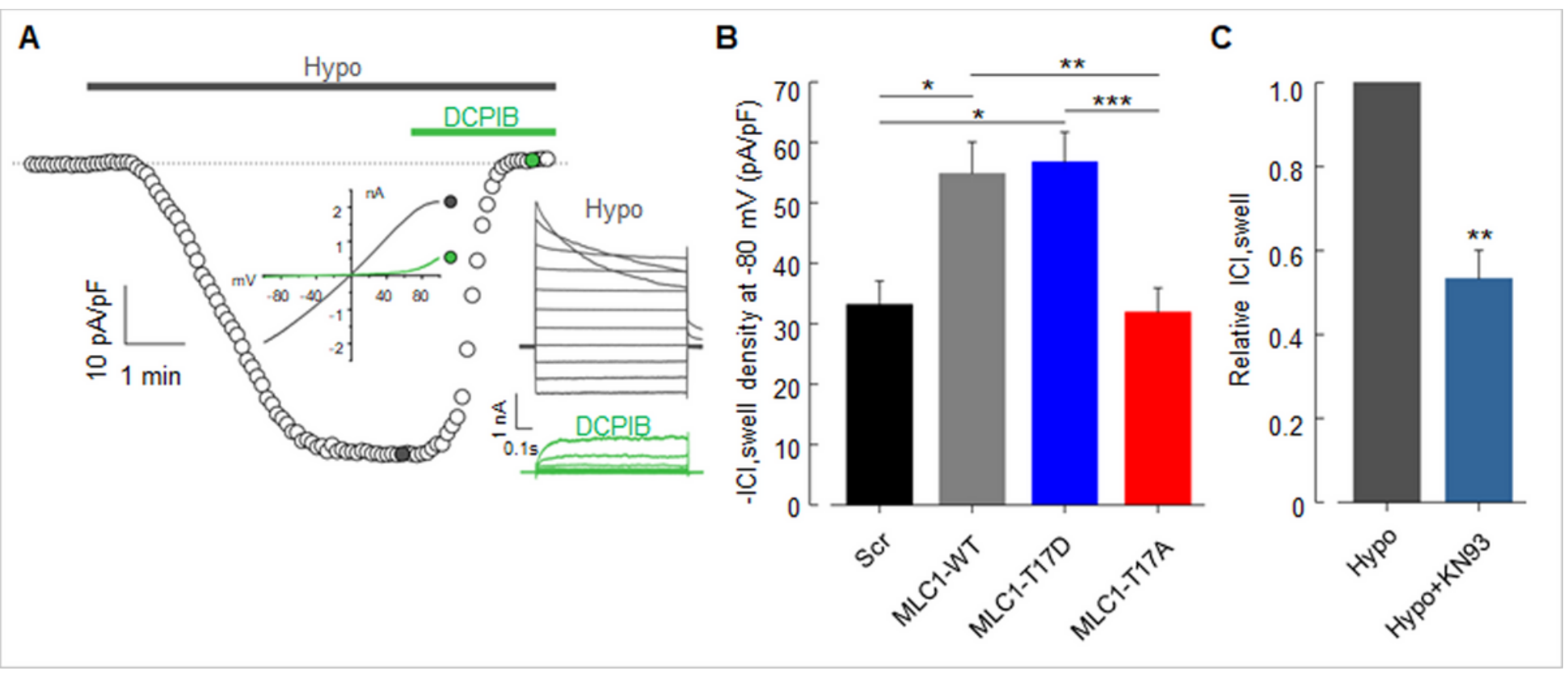

\section{Figure 7}

Electrophysiological recording of $\mathrm{ICl}$,swell currents in U251 cells. (A) Representative time course of $\mathrm{ICl}$,swell density $(\mathrm{pA} / \mathrm{pF})$ measured from current ramps at $-80 \mathrm{mV}$, the equilibrium potential for $\mathrm{K}+$ under our recording conditions, during application of hypotonic solution (grey bar) and upon addition of $10 \mu \mathrm{M}$ DCPIB (green bar). Insets: Left, representative current ramps from -100 to $100 \mathrm{mV}$ (600 ms duration) from a holding potential of $-40 \mathrm{mV}$, under hypotonic solution (grey trace) and hypotonic solution containing 10 $\mu \mathrm{M}$ DCPIB (green trace); Right, families of current traces evoked by applying $1 \mathrm{~s}$ voltage steps from -100 to $120 \mathrm{mV}$, in steps of $20 \mathrm{mV}$, from a holding potential of $-40 \mathrm{mV}$ in the presence of a hypotonic solution (grey traces), and in the presence of a hypotonic solution containing $10 \mu \mathrm{M} \mathrm{DCPIB} \mathrm{(green} \mathrm{traces).} \mathrm{(B)} \mathrm{Bar}$ plot showing the average current density measured at $-80 \mathrm{mV}$ during exposure to $30 \%$ hypotonic solution, in cells transfected with empty vector $(\mathrm{Scr}, \mathrm{n}=10)$ and $\mathrm{U} 251$ cells expressing a MLC1 WT protein (MLC1WT, $n=14$ ) or two different MLC1 proteins carrying point mutations T17D (constitutive phosphorylated mutant, MLC1-T17D, $n=9$ ) or T17A (unphosphorylatable mutant, MLC1-T17A, $n=14$ ). (C) Bar plotshowing the mean fractional ICl,swell in presence of $10 \mu \mathrm{M} \mathrm{KN}-93(n=3)$. Data are shown as mean \pm SEM; ${ }^{*} p<0.05$; $\star \star p<0.01, * \star * p<0.001$. 
A

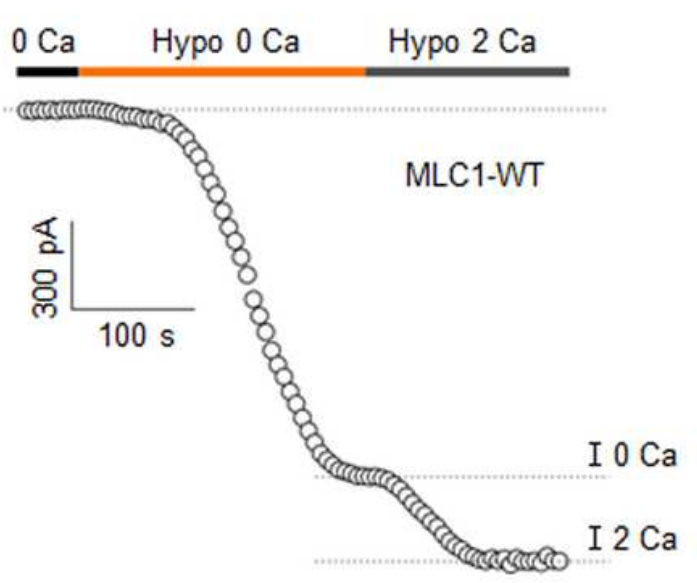

B

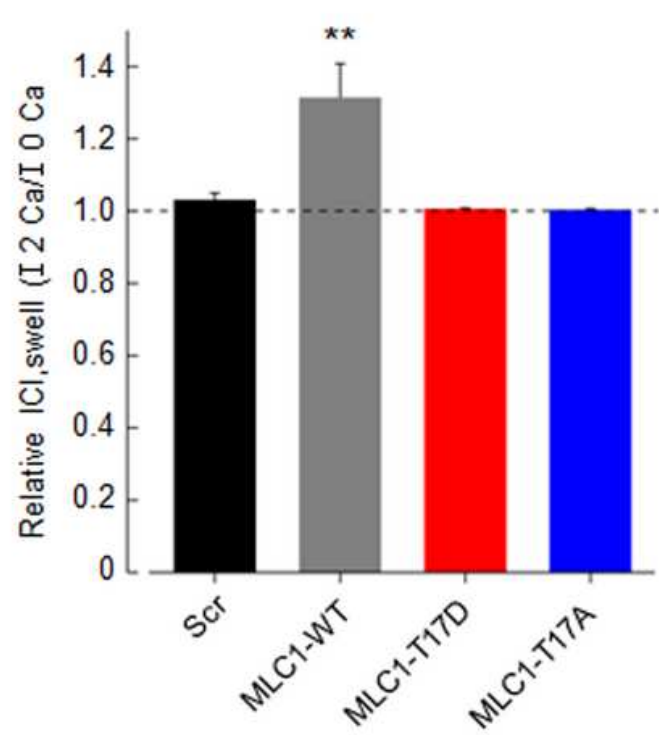

C

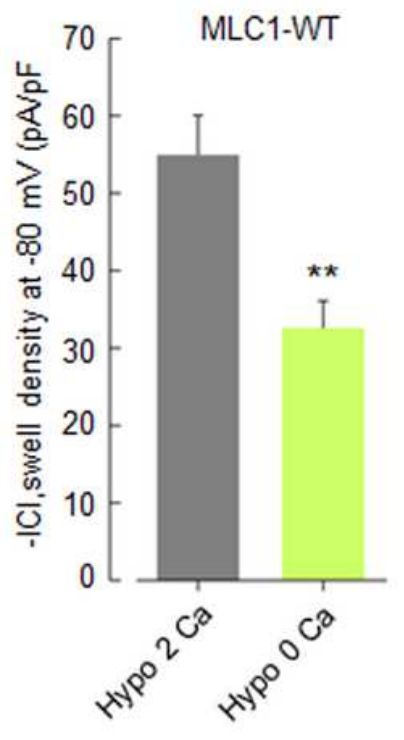

Figure 8

ICl,swellrecording in presence and absence of extracellular Ca2+. (A) Representative time course of $\mathrm{ICl}$,swell density during application of a $\mathrm{Ca} 2+$-free hypotonic solution (orange horizontal bar, $\mathrm{Hypo} \mathrm{O} \mathrm{Ca}$ ) and a $30 \%$ hypotonic solution containing $2 \mathrm{mM} \mathrm{Ca} 2+$ (grey horizontal bar, Hypo $2 \mathrm{Ca}$ ). (B) Bar plot showing the mean fractional ICl,swell elicited by Hypo 30\%, as normalized on the current activated by hypotonic 0-Ca (dashed line), in Scr ( $n=7), \operatorname{MLC1}-W T(n=7), \operatorname{MLC1-T17D~}(n=7)$ and MLC1-T17A $(n=7)$ U251 cells. (C) Bar plot showing the average current density during exposure to hypotonic solution, in the continuous presence (grey bar) or absence (light green bar) of external Ca2+, assessed in MLC1-WT cells. Data are shown as mean $\pm \mathrm{SEM} ;{ }^{* \star} \mathrm{p}<0.01$.

A

TG

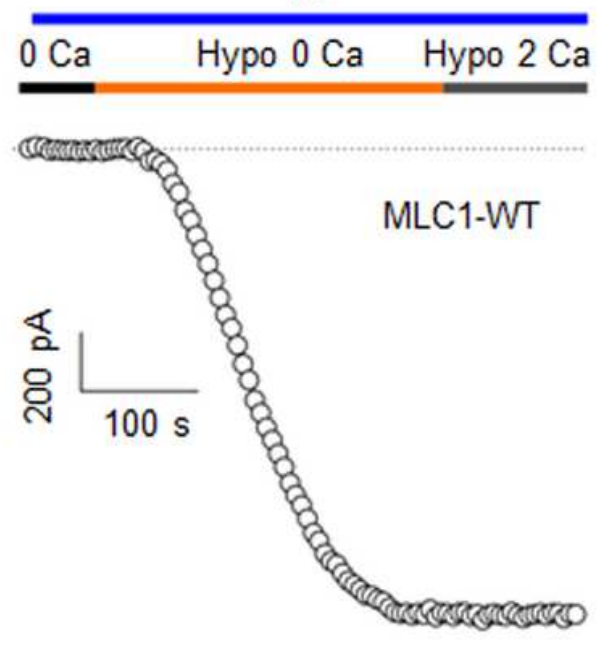

B

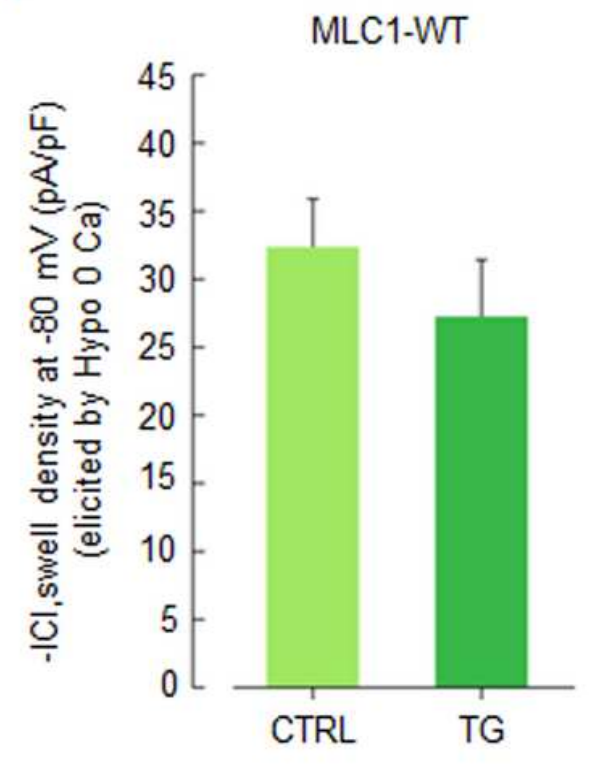

C

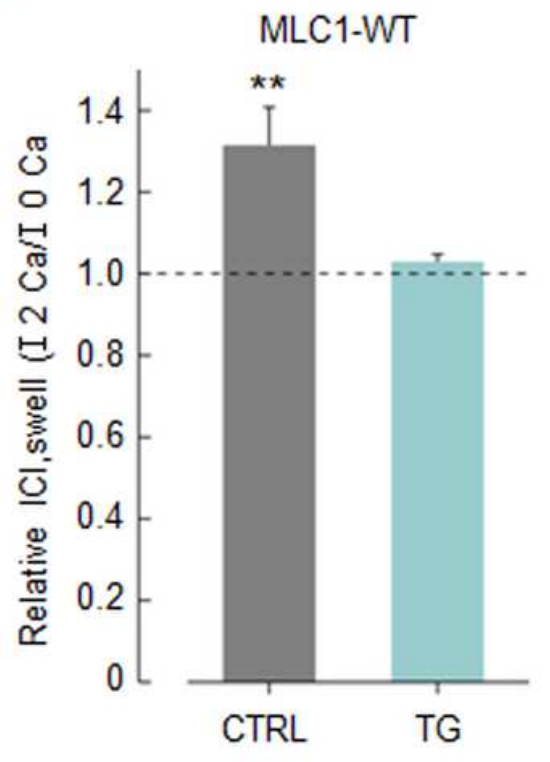

\section{Figure 9}


$\mathrm{ICl}$,swell recording in presence and absence of thapsigargin (TG)-induced $\mathrm{Ca} 2+$ store depletion. (A) Representative time course of $\mathrm{ICl}$,swell density during application of a $\mathrm{Ca} 2+$-free hypotonic solution (orange bar, Hypo $0 \mathrm{Ca}$ ) and in succession of a hypotonic solution containing $2 \mathrm{mM} \mathrm{Ca2+} \mathrm{(grey} \mathrm{bar,} \mathrm{hypo}$ 2-Ca2+), in MLC1-WT cells in the presence of prior store depletion induced with $1 \mu \mathrm{M}$ TG pre-treatment.

(B) Bar plot showing the average current density during exposure to hypotonic $0 \mathrm{Ca}$ + solution, in MLC1WT cells in the absence (CTRL) and presence of TG pre-treatment (TG), measured at $-80 \mathrm{mV}$. Data are shown as mean $\pm S E M ;{ }^{* \star} p<0.01$. (C) Bar plot showing the mean fractional ICl,swell elicited by Hypo $30 \%$, as normalized to the current activated by hypo0 $\mathrm{Ca} 2+$, in MLC1-WT cells either in the absence or presence of TG.

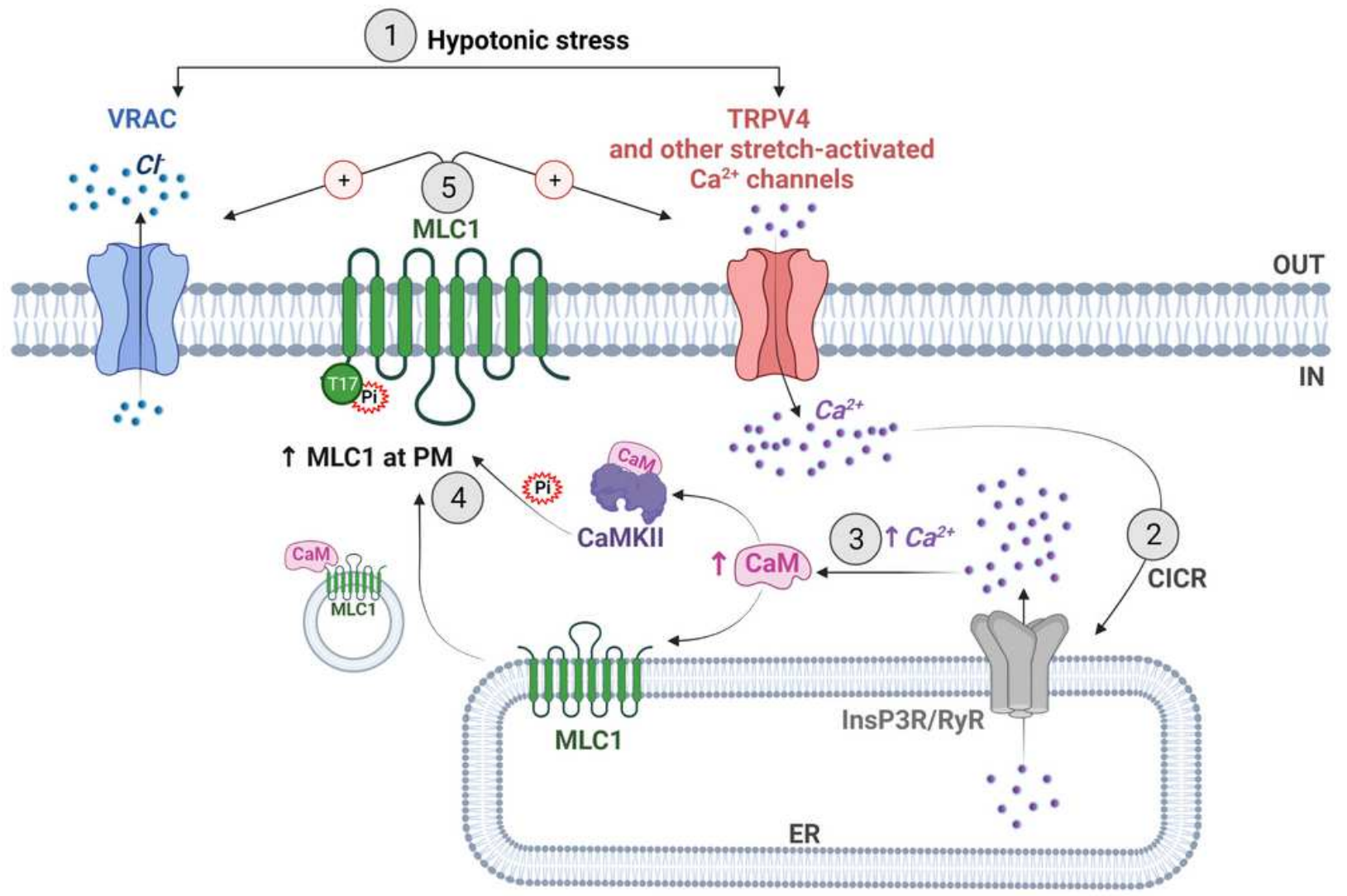

\section{Figure 10}

Proposed molecular mechanisms of the MLC1-induced Ca2+ regulation of VRAC. 1) Exposure to a hypotonic stress induces astrocyte (or astrocyte end-feet) swelling which triggers the opening of TRPV4 and other $\mathrm{Ca} 2+$ channels(voltage-dependent and mechanosensitive Ca2+ channels). 2) The entry of extracellular $\mathrm{Ca} 2+$ influx promotes $\mathrm{Ca} 2+$ release from the ER, likely mediated by the InsP3 (or/and Ryanodine) receptors, through the CICR mechanism. 3) The consequent elevation of intracellular $\mathrm{Ca} 2+$ is sensed by the Ca2+-binding protein calmodulin (CaM), which binds MLC1 favoring its trafficking to the 
PM and it activates the Ca2+/calmodulin-dependent protein kinase II (CaMKII). 4) By phosphorylating the threonine aa at position 17 of the MLC1 protein (T17), CaMKII promotes MLC1 PM stabilization and its functional activation. 5) Phosphorylated MLC1 potentiates TRPV4 and VRAC channels favoring ICl,swell and regulatory volume decrease.

\section{Supplementary Files}

This is a list of supplementary files associated with this preprint. Click to download.

- Supplementarymaterial.pdf 